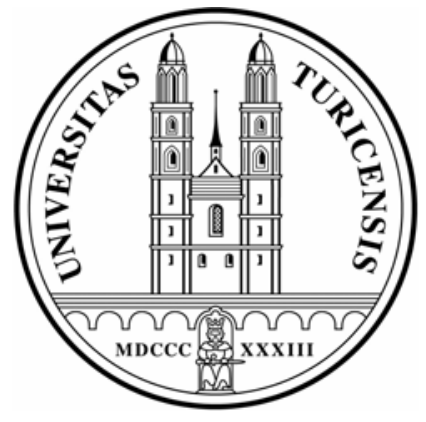

Institute for Empirical Research in Economics

University of Zurich

Working Paper Series

ISSN 1424-0459

Working Paper No. 312

To React or Not? Fiscal Policy, Volatility and Welfare in the EU-3

Jim Malley, Apostolis Philippopoulos and Ulrich Woitek

February 2007 


\title{
To React or Not? Fiscal Policy, Volatility and Welfare in the EU-3*
}

\author{
Jim Malley \\ University of Glasgow and CESifo \\ Apostolis Philippopoulos \\ Athens University of Economics \& Business and CESifo \\ Ulrich Woitek \\ University of Zurich and CESifo
}

February 2007

\begin{abstract}
This paper develops a dynamic stochastic general equilibrium model to examine the quantitative macroeconomic implications of countercyclical fiscal policy for France, Germany and the UK. The model incorporates real wage rigidity which is the particular market failure justifying policy intervention. We subject the model to productivity shocks and use either government consumption or investment to react to the output gap or the public debt-to-output ratio. If the object of fiscal policy is purely to stabilize output or debt volatility, then our results suggest substantial reductions can be obtained, especially with respect to output. In stark contrast, however, a formal general equilibrium welfare assessment of the volatility implications of these alternative instrument/target combinations reveals the welfare gains from active policy, measured as a share of consumption, to be very modest.
\end{abstract}

Keywords: Fiscal Policy, Welfare, Europe JEL: E6, H5

${ }^{*}$ We would like to thank Costas Angelopoulos, Paul De Grauwe, Harris Dellas, Jayasri Dutta, Marco Ercolani, Burkhard Heer, Campbell Leith, Ioana Moldovan, Johann Scharler, Peter Sinclair, Mike Wickens and seminar participants at the Universities of Bern, Birmingham, Stirling and the CESifo MacroArea conference (2006) for helpful comments. The usual disclaimer applies. 
The empirical evidence points to the adoption of increasingly countercyclical polices by governments in OECD countries over the postwar period. [Galí, 2005]

\section{Introduction}

Despite the relative neglect of fiscal compared to monetary policy since the 1970s, there has been somewhat of a revival in the interests of European policymakers and academics for the need and scope for counter-cyclical fiscal stabilization policy (see, e.g. Andres and Domenech (2006), the papers in the CESifo Economic Studies (2005) volume and recent theoretical papers on feedback fiscal policy, e.g. Aloi et al. (2003), Christiano and Harrison (1999) and Guo and Lansing (1998)). While most theorists seem to prefer the use of automatic stabilizers to active ${ }^{1}$ policy rules (and even more to discretionary policy), in practice, as pointed out by Galí (2005) above, policymakers do change their fiscal policies when the economic fundamentals change.

In Europe, post Maastricht, this is obviously related to the fact that monetary policy is no longer an option for individual countries, but also to the recent sustained slow growth in the French and German economies. This renewed interest in countercyclical fiscal stabilization policy begs a number of important questions regarding which, if any, of the potential fiscal instruments available to policymakers will be able to deliver the desired degree of stability. More importantly, will this stability be welfare improving? ${ }^{2}$

At the same time, due to the conditions of the Maastricht Treaty (MT) and the Stability and Growth Pact (SGP), there have also been recommendations in Europe to correct public finance imbalances by adding, for instance, the public debt-to-GDP ratio, or the budget deficit-to-GDP ratio, to the set of fundamentals that fiscal authorities should respond to. For instance, these rules suggest that government spending should fall whenever the public debt-to-GDP ratio exceeds the critical value of $60 \%$ or when the budget deficit-to-GDP ratio is in excess of $3 \%$.

With this background in mind, we construct a dynamic stochastic general equilibrium (DSGE) model to examine the quantitative macroeconomic implications of countercyclical state-contingent fiscal policies for France, Germany and the U.K.. These rules imply that those charged with the conduct

\footnotetext{
${ }^{1}$ We will use the terms state-contingent, state-dependent, active and feedback interchangeably.

${ }^{2}$ Note that policymakers may even follow pro-cyclical policy which further undermines the role of automatic stabilizers. Pro-cyclical policies are typically associated with political distortions. It is not the aim of this paper to analyse the effects of these policies.
} 
of fiscal policy adjust their policy instruments to the current economic situation, in a manner that is beyond the role played by automatic stabilizers. In an attempt to more closely replicate the output dynamics that appear in macroeconomic data, our model includes capital adjustment costs and real wage rigidity. The latter is particularly relevant for Europe and is the market failure justifying policy intervention in our setup. Actually, it is widely believed that real wage rigidity is one of the most important distortions in most European economies.

The model's structural parameters for France, Germany and the UK are obtained using standard calibration methods. To assess the fit of these DSGE models to that of unrestricted VARs, we employ Watson's (1993) root mean square approximation error measure for calibrated models. We show that the model fit generally improves substantially with the inclusion of capital adjustment costs and real wage rigidity.

Our policy instruments include the three major items of public spending (i.e. public consumption, investment and transfers) and income taxes. The government's allocative role in our setup is the provision of public consumption services that augment household's utility and public investment that enhances public capital entering the firm's production function. When modelling feedback policy, we allow public consumption and investment to respond endogenously to the cyclical state of the economy measured by the output gap and/or the deviation of the public debt-to-GDP ratio from a $60 \%$ target. $^{3}$ When such counter-cyclical reaction is switched off, policymakers make use of automatic stabilizers only. In other words, we study two of the main responsibilities of the government, namely the stabilization of the macroeconomy as well as the re-allocation of resources via the provision of public goods and services.

We next subject the model to both temporary and permanent stochastic productivity shocks to first understand the purely stabilizing effects on output and debt of moving from passive to active fiscal policy. We then extend the exercise to evaluate the quantitative welfare implications of these reductions in volatility. To conduct a general equilibrium welfare analysis, we follow the linear quadratic approach of Rotemberg and Woodford (1997) and Woodford (2003).

Our main findings are as follow. When the object of active fiscal policy

\footnotetext{
${ }^{3}$ Given that income tax rates change infrequently via reforms (see e.g. King and Rebelo (1999, p. 974), due to nature of the political and legal processes involved in setting them, they are not state contingent in our setup. Also since transfers do not play an allocative role in our model, their share in output will remain constant.
} 
is to stabilize output or debt volatility, then substantial reductions in their standard deviation can be obtained, especially with respect to output. However, there is a trade-off: when policymakers intervene to stabilize output (resp. debt), this is achieved at the cost of destabilizing public debt (resp. output). Also, when we use public consumption as a policy instrument, the effects are higher in magnitude than when we employ government investment. Further, the cross-country results suggest that the direct stabilizing effects increase with the degree of real wage rigidity.

But, even when there are substantial reductions in the standard deviation of individual variables as we move from passive to active policy, these differences are translated into very small gains in terms of general equilibrium welfare. This is a robust result and applies across policy instruments and the size or duration of shocks. This mainly happens because "stabilizing one target destabilizes another" so that net effects are negligible (stabilization takes place via non lump-sum policy instruments so it always has some resource and welfare implications).

Nevertheless, within the world of small welfare effects, it is worth reporting the following. When real wage rigidity is relatively low (like in Germany and the UK), counter-cyclical output stabilizing policy plays its expected, welfare-enhancing role. On the other hand, the same policy hurts the aggregate economy when real wage rigidity is relatively high (like in France). To understand this seemingly paradoxical result recall that real wage rigidity means that current allocations and prices depend myopically on their lagged values. When this dependence is high, so that the current state of the economy matters little, it is not a good idea to absorb output fluctuations by varying the policy instruments. This simply deteriorates the myopic dependence on the past. In other words, in a sclerotic economy, exposing the economy to the current cyclical real situation is welfare enhancing. Following the same logic, reaction to a public debt target is deteriorating (resp. improving) for countries with relatively flexible (resp. sclerotic) labour markers. This is because debt stabilization comes at the cost of higher output volatility; the latter is beneficial only for countries with relatively rigid labour markets.

The rest of the paper is organized as follows. Sections 2 and 3 set out the theoretical and parameterized models while sections 4 and 5 contain the results and conclusions respectively. Details pertaining to the steady-state, the linearized system, model solution and evaluation, and welfare analysis, are contained in Appendices A-D respectively. 


\section{The Theoretical Model}

The DSGE model we develop below is populated by a large number of identical infinitely-lived private agents (households and firms). The government imposes distorting taxes to finance public consumption, investment and transfers. The government's policy instruments can follow feedback rules which depend on both exogenous factors and the endogenous state of the economy. We allow for the well-known persistence of macroeconomic variables by including capital adjustment costs and real wage rigidity.

\subsection{Households}

There is a large number of identical households indexed by the superscript $h$, where $h=1,2, \ldots N_{t}$. The population size at time $t$ is $N_{t}=n^{t}$, where $n \geq 1$ is a constant rate of growth. The preferences of the representative household are given by the following time-separable utility function:

$$
E_{0} \sum_{t=0}^{\infty} \beta^{t} U\left(C_{t}^{h}, L_{t}^{h}, \bar{G}_{t}^{c}\right)
$$

where $E_{0}$ is the expectations operator; $C_{t}^{h}$ is private consumption of household $h$ at time $t ; L_{t}^{h}$ is the leisure time of household $h$ at time $t ; \bar{G}_{t}^{c}$ is average (per household) consumption services provided by the government at time $t$; and $0<\beta<1$ is the subjective rate of time preference. The household divides its time endowment between leisure and work so that $L_{t}^{h}+H_{t}^{h}=1$.

The instantaneous utility function is increasing in its three arguments, concave and satisfies the Inada conditions. For simplicity we use the following log-linear form for utility:

$$
U_{t}=\ln C_{t}^{h}+\mu \ln \left(1-H_{t}^{h}\right)+\nu \ln \bar{G}_{t}^{c}
$$

where, $(\mu, \nu)>0$ are the weights given to leisure and public consumption respectively relative to private consumption.

Each household can save in the form of capital, $I_{t}^{h}$, and government bonds, $D_{t}^{h}$. It receives interest income, $r_{t}^{k} K_{t}^{h}$, from accumulated capital and $r_{t}^{b} B_{t}^{h}$ from accumulated bonds, where $r_{t}^{k}$ and $r_{t}^{b}$ are the gross returns to capital and bonds respectively. Labor augmenting technology progress at time $t$ is $Z_{t}=z^{t}$, where $z \geq 1$ is a constant growth rate. Given $Z_{t}$, the household receives labor income, $w_{t} z^{t} H_{t}^{h}$, per unit of effective time worked. Finally, the household receives dividends paid by firms, $\Pi_{t}^{h}$, and average (per household) transfers paid by the government, $\bar{G}_{t}^{t}$. Accordingly, the budget constraint of 
the household is:

$$
C_{t}^{h}+I_{t}^{h}+D_{t}^{h}=\left(1-\tau_{t}^{y}\right)\left(r_{t}^{k} K_{t}^{h}+w_{t} z^{t} H_{t}^{h}+\Pi_{t}^{h}+r_{t}^{b} B_{t}^{h}\right)+\bar{G}_{t}^{t}
$$

where is $0<\tau_{t}^{y}<1$ is the rate of income tax at $t$. Private holdings of government bonds and capital grow according to the following evolution equations:

$$
B_{t+1}^{h}=B_{t}^{h}+D_{t}^{h}
$$

and

$$
K_{t+1}^{h}=\left(1-\delta^{p}\right) K_{t}^{h}+I_{t}^{h}-\frac{\alpha^{p}}{2}\left(\frac{I_{t}^{h}}{K_{t}^{h}}-\frac{I^{h}}{K^{h}}\right)^{2} K_{t}^{h}
$$

where $0 \leq \delta^{p} \leq 1$ is a constant depreciation rate, $\alpha^{p} \geq 0$ captures internal adjustment costs on gross investment, and $I^{h}$ and $K^{h}$ are the steady-state values of equilibrium investment and capital stock respectively. In common with the $R B C$ literature, adjustment costs will be zero in the long run.

Households act competitively by taking market prices, policy variables and aggregate outcomes as given. Thus, each household chooses $\left\{C_{t}^{h}, H_{t}^{h}\right.$, $\left.L_{t}^{h}, I_{t}^{h}, D_{t}^{h}, K_{t+1}^{h}, B_{t+1}^{h}\right\}_{t=0}^{\infty}$ to maximize (1) subject to (2)-(5), the restriction $L_{t}^{h}+H_{t}^{h}=1$ and initial conditions for $K_{0}^{h}$ and $B_{0}^{h}$. The first-order conditions include the constraints $(3)-(5)$, the optimality condition for labor supply, $(6 a)$, and the Euler-equations for private capital and government bonds (6b$6 c)$ :

$$
\begin{gathered}
w_{t}=\frac{\mu C_{t}^{h}}{\left(1-H_{t}^{h}\right)\left(1-\tau_{t}^{y}\right) z^{t}} \equiv M R S_{t} \\
\frac{1}{C_{t}^{h}}=\beta E_{t}\left[Z_{t+1}^{k}\left(\frac{1}{C_{t+1}^{h}}\right)\right] \\
\left(\frac{1}{C_{t}^{h}}\right)=\beta E_{t}\left[Z_{t+1}^{b}\left(\frac{1}{C_{t+1}^{h}}\right)\right]
\end{gathered}
$$

where we define

$$
\widetilde{I}_{t}^{h} \equiv \frac{I_{t}^{h}}{K_{t}^{h}}-\frac{I^{h}}{K^{h}}
$$

$Z_{t+1}^{k} \equiv\left[1-\alpha^{p} \widetilde{I}_{t}^{h}\right]\left\{\left(1-\tau_{t+1}^{y}\right) r_{t+1}^{k}+\frac{1-\delta^{p}+\alpha^{p} \widetilde{I}_{t+1}^{h}\left(\frac{I_{t+1}^{h}}{K_{t+1}^{h}}\right)-\frac{\alpha^{p}}{2}\left(\widetilde{I}_{t+1}^{h}\right)^{2}}{1-\alpha^{p} \widetilde{I}_{t+1}^{h}}\right\}$

and

$$
Z_{t+1}^{b} \equiv 1+\left(1-\tau_{t+1}^{y}\right) r_{t+1}^{b}
$$




\section{$2.2 \quad$ Firms}

There is a large number of identical firms indexed by the superscript $f$, where $f=1,2, \ldots N_{t}{ }^{4}$ The representative firm produces a homogeneous final product, $Y_{t}^{f}$, by using private capital, $K_{t}^{f}$, private labor, $H_{t}^{f}$, and average (per firm) public capital, $\bar{K}_{t}^{g}$. The production function of the firm takes the form:

$$
Y_{t}^{f}=A_{t}\left(K_{t}^{f}\right)^{\alpha_{1}}\left(z^{t} H_{t}^{f}\right)^{\alpha_{2}}\left(\bar{K}_{t}^{g}\right)^{1-\alpha_{1}-\alpha_{2}}
$$

where $A_{t}$ is exogenous stochastic productivity (whose motion is specified below) and $0<\alpha_{1}, \alpha_{2}<1$ are the productivity of private capital and labor respectively. We follow e.g. Lansing (1998) by assuming CRS in the three factors.

Firms act competitively by taking market prices, policy variables and aggregate outcomes as given. Thus, each firm chooses $K_{t}^{f}$ and $H_{t}^{f}$ to maximize

$$
\Pi_{t}^{f} \equiv\left(1-\tau_{t}^{s}\right) Y_{t}^{f}-r_{t}^{k} K_{t}^{f}-w_{t} z^{t} H_{t}^{f}
$$

where $-1<\tau_{t}^{s}<0$ denotes an output subsidy and vice-versa for $0<$ $\tau_{t}^{s}<1 .^{5}$ The returns to capital and labor are given by:

$$
\begin{aligned}
& r_{t}^{k}=\frac{\alpha_{1}\left(1-\tau_{t}^{s}\right) Y_{t}^{f}}{K_{t}^{f}} \\
& w_{t}=\frac{\alpha_{2}\left(1-\tau_{t}^{s}\right) Y_{t}^{f}}{z^{t} H_{t}^{f}} .
\end{aligned}
$$

\subsection{Wage setting}

To avoid further complicating the model but to also help it replicate the stylized facts in Europe regarding inertia in wage adjustment, we follow the setup employed in Blanchard and Galí (2005). In particular, we assume that:

$$
w_{t}=\left(w_{t-1}\right)^{\eta}\left(M R S_{t}\right)^{1-\eta}
$$

where $0 \leq \eta \leq 0$ measures the degree of wage sluggishness and $M R S_{t}$ is given by (6a). This specification has the following advantages (i) if $\eta=0$ then the standard neoclassical model obtains; (ii) in the steady-state, i.e. when $w_{t}=w_{t-1}=w$, it follows that again $w=M R S$; and (iii) as pointed out in

\footnotetext{
${ }^{4}$ For simplicity we assume that the number of firms equals the number of households in each period.

${ }^{5}$ This tax will only be used to conduct our welfare analysis below (see subsection 6.4.4 for details). Having this in mind, it will suffice to use a flat rate over time, i.e. $\tau_{t}^{s} \equiv \tau_{0}^{s}$.
} 
Blanchard and Galí (2005), this ad hoc relation is consistent with a number of possible sources of rigidity in European labor markets, e.g. institutional, legal and socio-political rigidities and safety nets, etc..

\subsection{Government}

The government budget constraint at $t$ is:

$$
\begin{aligned}
& G_{t}^{c}+G_{t}^{i}+G_{t}^{t}+\left(1+r_{t}^{b}\right) B_{t} \\
= & B_{t+1}+\tau_{t}^{y} \sum_{h=1}^{N_{t}}\left(r_{t}^{k} K_{t}^{h}+w_{t} z^{t} H_{t}^{h}+\Pi_{t}^{h}+r_{t}^{b} B_{t}\right)+\tau_{t}^{s} \sum_{f=1}^{N_{t}} Y_{t}^{f}
\end{aligned}
$$

where $G_{t}^{c}, G_{t}^{i}, G_{t}^{t}$ are respectively total government consumption, total government investment and total government transfers at time $t$, and $B_{t+1}$ is the end-of-period total stock of bonds issued by the government. Government investment, $G_{t}^{i}$, is used to augment the stock of public capital, $K_{t}^{g}$, whose motion is given by:

$$
K_{t+1}^{g}=\left(1-\delta^{g}\right) K_{t}^{g}+G_{t}^{i}
$$

where $0 \leq \delta^{g} \leq 1$ is a constant depreciation rate.

\subsection{Decentralized competitive equilibrium}

Given the paths of technology, population and labor augmenting technical progress $\left\{A_{t}, N_{t}, Z_{t}\right\}_{t=0}^{\infty}$, the economic policy instruments $\left\{G_{t}^{c}, G_{t}^{i}, G_{t}^{t}, \tau_{t}^{y}\right.$, $\left.\tau_{t}^{s}\right\}_{t=0}^{\infty}$ and initial conditions for the state variables $\left\{B_{0}, K_{0}, K_{0}^{g}, w_{0}\right\}$, a decentralized competitive equilibrium $(D C E)$ is defined to be a sequence of allocations $\left\{Y_{t}, C_{t}, I_{t}, H_{t}, K_{t+1}, K_{t+1}^{g}, B_{t+1}\right\}_{t=0}^{\infty}$ and prices $\left\{r_{t}^{k}, r_{t}^{b}, w_{t}\right\}_{t=0}^{\infty}$ such that: (i) households maximize utility; (ii) firms maximize profits; (iii) the capital, labor, and bond markets clear, i.e. $\sum_{h=1}^{N_{t}} K_{t}^{h}=\sum_{h=1}^{N_{t}} K_{t}^{f} ; \sum_{h=1}^{N_{t}} H_{t}^{h}=\sum_{h=1}^{N_{t}} H_{t}^{f}$; $\sum_{h=1}^{N_{t}} B_{t}^{h}=B_{t}$, respectively; and (iv) the government budget constraint given by $(9 a)$ and the motion in $(9 b)$ are satisfied. Note that market clearing values will be denoted by letters without the superscript $h$ and $f$.

We next transform the relevant aggregate quantities to stationary variables by defining $x_{t}=X_{t} /(n z)^{t}$, where $X_{t} \equiv\left(Y_{t}, C_{t}, I_{t}, K_{t}, K_{t}^{g}, B_{t}, G_{t}^{c}, G_{t}^{i}\right.$, $\left.G_{t}^{t}\right)$. An exception is $h_{t}=H_{t} / n^{t}$. Accordingly, small letters denote quantities in per capita and efficiency units. Also note that $a_{t} \equiv A_{t}$. Our $C E$ derived in the previous sub-sections can now be rewritten in stationary form as follows:

$$
y_{t}=a_{t}\left(k_{t}\right)^{\alpha_{1}}\left(h_{t}\right)^{\alpha_{2}}\left(k_{t}^{g}\right)^{1-\alpha_{1}-\alpha_{2}}
$$




$$
\begin{gathered}
y_{t}=c_{t}+i_{t}+g_{t}^{c}+g_{t}^{i} \\
n z k_{t+1}=\left(1-\delta^{p}\right) k_{t}+i_{t}-\frac{\alpha^{p}}{2}\left(\widetilde{i}_{t}\right)^{2} k_{t} \\
w_{t}=\left(w_{t-1}\right)^{\eta}\left(\frac{\mu c_{t}}{\left(1-h_{t}\right)\left(1-\tau_{t}^{y}\right)}\right)^{1-\eta} \\
\frac{1}{c_{t}}=\frac{\beta}{n z} E_{t}\left[z_{t+1}^{k}\left(\frac{1}{c_{t+1}}\right)\right] \\
\frac{1}{c_{t}}=\frac{\beta}{n z} E_{t}\left[z_{t+1}^{b}\left(\frac{1}{c_{t+1}}\right)\right] \\
n z k_{t+1}^{g}=\left(1-\delta^{g}\right) k_{t}^{g}+g_{t}^{i} \\
g_{t}^{c}+g_{t}^{i}+g_{t}^{t}+\left(1+r_{t}^{b}\right) b_{t} \\
n z b_{t+1}+\tau_{t}^{y}\left[y_{t}+r_{t}^{b} b_{t}\right]+\tau_{t}^{s} y_{t}
\end{gathered}
$$

where the stationary returns to capital and labor are:

$$
\begin{aligned}
& r_{t}^{k}=\frac{\alpha_{1}\left(1-\tau_{t}^{s}\right) y_{t}}{k_{t}}, \\
& w_{t}=\frac{\alpha_{2}\left(1-\tau_{t}^{s}\right) y_{t}}{h_{t}}
\end{aligned}
$$

and where we have the definitions:

$$
\begin{gathered}
\widetilde{i}_{t} \equiv \frac{i_{t}}{k_{t}}-\frac{i}{k} \\
z_{t+1}^{k} \equiv\left[1-\alpha^{p} \widetilde{i}_{t}\right]\left\{\left(1-\tau_{t+1}^{y}\right) r_{t+1}^{k}+\frac{1-\delta^{p}+\alpha^{p} \widetilde{i}_{t+1}\left(\frac{i_{t+1}}{k_{t+1}}\right)-\frac{\alpha^{p}}{2}\left(\widetilde{i}_{t+1}\right)^{2}}{1-\alpha^{p} \widetilde{i}_{t+1}}\right\},
\end{gathered}
$$

and

$$
z_{t+1}^{b} \equiv 1+\left(1-\tau_{t+1}^{y}\right) r_{t+1}^{b} .
$$

In other words, the stationary $D C E$ is defined by the above system of ten nonlinear stochastic difference equations in $\left\{y_{t}, c_{t}, i_{t}, h_{t}, k_{t+1}, k_{t+1}^{g}, r_{t}^{b}\right.$, $\left.b_{t+1}, w_{t}, r_{t}^{k}\right\}_{t=0}^{\infty}$ for given paths of technology, $\left\{a_{t}\right\}_{t=0}^{\infty}$ and the independent policy instruments, $\left\{g_{t}^{c}, g_{t}^{t}, g_{t}^{i}, \tau_{t}^{y}, \tau_{t}^{s}\right\}_{t=0}^{\infty}$ whose evolution is explained in the next sub-section. 


\subsection{The motion of technology and fiscal policy instru- ments}

Following most of the $R B C$ literature, we assume that the stochastic process determining $a_{t}$ is an exponential first-order Markov process

$$
a_{t}=a_{0}^{\left(1-\rho^{a}\right)} a_{t-1}^{\rho^{a}} e^{\varepsilon_{t}}
$$

where $a_{0}>0$ is a constant, $0<\rho^{a}<1$ is the autoregressive parameter and $\varepsilon_{t} \sim i i d\left(0, \sigma^{2}\right)$ are the random shocks to productivity.

Following e.g. Aloi et al. (2003), Christiano and Harrison (1999) and Guo and Lansing (1998), the policy instrument rates $\mathbf{p}_{t}=\left[\begin{array}{lll}g_{t}^{c} / y_{t} & g_{t}^{i} / y_{t} & g_{t}^{t} / y_{t}\end{array}\right.$ $\left.\tau_{t}^{y} \tau_{t}^{s}\right]^{\prime}$ can follow feedback rules of the form

$$
\mathbf{p}_{t}=\widetilde{\mathbf{p}}_{t}\left(\mathbf{f}_{t} / \mathbf{f}\right)^{\gamma}
$$

where $\widetilde{\mathbf{p}}_{t}$ is the exogenous or non-state contingent part of the policy instrument rate and $\left(\mathbf{f}_{t} / \mathbf{f}\right)^{\gamma}$ is its feedback or state contingent component. We assume that $\mathbf{f}_{t} \equiv\left[y_{t} \frac{b_{t}}{y_{t}}\right]^{\prime}$ and hence $\mathbf{f}=\left[y \frac{b}{y}\right]^{\prime}$. Thus the authorities can react to deviations of output and the public debt-to-output ratio from their steady-state values. Finally, $\gamma$ is a vector of feedback policy coefficients that can be positive, negative or zero depending on whether the policy instrument rate is used pro-cyclically, counter-cyclically or a-cyclically.

Thus our setup can allow for policy reactions to the output gap, which is the most common form of counter-cyclical policy, and to public debt to output ratio relative to the $60 \%$ value implicitly required by the SGP (see Appendix A for details). ${ }^{6}$ The former is an indicator of economic activity and a flow variable. The latter is an indicator of public finances and a stock variable. Note that our feedback policy rules are also in accordance with Tanzi's suggestion (Tanzi, CESifo Forum, 3/2005, p. 64) that "countercyclical fiscal policy should not be abandoned in depressions and it could be tried in milder slowdowns when the fiscal accounts of a country are in good initial conditions". Note finally that, despite the recent loosening of the SGP, national policymakers continue to take into account the fiscal accounts and imbalances.

\footnotetext{
${ }^{6}$ The CESifo DICE Report, 2/2004, pp. 85-86, points to other possible fiscal rules, not considered in this study but which are used or being considered in various OECD countries. For instance, there can also be ceilings on different items of government spending, or golden rules stating that net government borrowing should not exceed net public investment. Also, in the EU countries, there is the additional 3\% of GDP ceiling on net government borrowing.
} 
For the reasons discussed so far (see footnotes 3 and 5 above), we assume that $g_{t}^{t} / y_{t}, \tau_{t}^{y}$, and $\tau_{t}^{s}$ do not contain a state contingent component. Hence the relevant elements of vector $\gamma$ are zero. We also assume that the exogenous part of all instruments except $\tau_{t}^{y}$ is constant. ${ }^{7}$ The above discussion implies the following specific policy rules

$$
\begin{gathered}
\frac{g_{t}^{c}}{y_{t}}=g_{0}^{c}\left(\frac{y_{t}}{y}\right)^{\gamma_{y}^{g}}\left(\frac{y_{t} / b_{t}}{y / b}\right)^{\gamma_{b}^{g}} \\
\frac{g_{t}^{i}}{y_{t}}=g_{0}^{i}\left(\frac{y_{t}}{y}\right)^{\gamma_{y}^{i}}\left(\frac{y_{t} / b_{t}}{y / b}\right)^{\gamma_{b}^{i}} \\
\frac{g_{t}^{t}}{y_{t}}=g_{0}^{t} \\
\tau_{t}^{y}=\left(\tau_{0}^{y}\right)^{\left(1-\rho^{\tau}\right)}\left(\tau_{t-1}^{y}\right)^{\rho^{\tau}}
\end{gathered}
$$

where the three constants $g_{0}^{c}, g_{0}^{i}, g_{0}^{t}$ represent the steady-state shares of each component of public spending to output and $\tau_{0}^{y}$ is the steady-state direct $\operatorname{tax}^{8}$

The stationary long-run DCE and its linearized version are presented in Appendices A and B respectively.

\section{The Parameterized Model}

The model's structural parameters relating to preferences, production and capital accumulation are next calibrated using annual data for France, Germany and the United Kingdom from 1970-2005. The individual country data are obtained from the OECD, IMF and ECFIN. The OECD databases include: (i) Main Economic Indicators (MEI); (ii) Economic Outlook (EO); and (iii) International Sectoral Database (ISDB). The IMF data is from the International Financial Statistics (IFS) database. Effective tax rates were obtained from ECFIN. Finally, to obtain empirical support for our modelling choices, we assess the fit of our calibrated DCE models using Watson's (1993) root mean square approximation error (RMSAE) measure.

\footnotetext{
${ }^{7}$ For reasons which will become clear when we develop the welfare analysis below, we allow direct taxes to follow a deterministic AR(1) process.

${ }^{8}$ As mentioned in footnote $(5)$ the subsidy rate, $\tau_{t}^{s}$ is equal to its long-run steady state, $\tau_{0}^{s}$ for all $t$, see subsection 6.4 .4 for its determination.
} 


\subsection{Calibrated parameters}

The parameters of our model and their calibrated values are listed in Table 1. Average labour's share, $\alpha_{2}$, is obtained directly from the ISDB dataset. An approximate value across our 3-countries of 0.6 has also been used by Smets and Wouters (2003) for the Euro Area aggregate. Private and public capital's shares, $\alpha_{1}$ and $\left(1-\alpha_{1}-\alpha_{2}\right)$ respectively, are obtained by decomposing the implied aggregate capital share into private and public shares using average private and public investment shares from the EO database. Our implied values for the productivity of public capital, 0.053, 0.046, 0.015 for Germany, France and the UK respectively, are similar in magnitude to those found in for example, Baxter and King (1993) and Lansing (1998) for the U.S..

\begin{tabular}{lllll}
\hline & \multicolumn{4}{c}{ Table 1: Parameter Values } \\
\hline \hline parameter & Ger & Fra & Gbr & definition \\
$0<\alpha_{1}<1$ & 0.36 & 0.38 & 0.38 & productivity of private capital \\
$0<\alpha_{2}<1$ & 0.59 & 0.58 & 0.60 & productivity of labor \\
$\alpha^{p} \geq 0$ & 2.00 & 2.00 & 2.00 & adjustment costs on private capital \\
$0<\beta<1$ & 0.96 & 0.97 & 0.98 & rate of time preference \\
$0 \leq \delta^{g} \leq 1$ & 0.10 & 0.10 & 0.10 & depreciation rate on public capital \\
$0 \leq \delta^{p} \leq 1$ & 0.10 & 0.10 & 0.10 & depreciation rate on private capital \\
$0 \leq \eta \leq 1$ & 0.80 & 0.88 & 0.79 & degree of real wage rigidity \\
$\mu>0$ & 2.11 & 2.09 & 1.88 & leisure weight in utility \\
$n \geq 1$ & 1.011 & 1.007 & 1.003 & population growth \\
$\nu>0$ & 0.10 & 0.10 & 0.10 & public consumption weight in utility \\
$0 \leq \tau_{0}^{y}<1$ & 0.31 & 0.30 & 0.29 & direct tax rate \\
$z \geq 1$ & 1.016 & 1.010 & 1.021 & labor augmenting tech progress \\
\hline
\end{tabular}

Since we do not have data pertaining to capital adjustment costs and since our specification of these costs is based on Canova (2002), we follow this study and Cooper and Haltiwanger (2002) and set $\alpha^{p}=2$ for all countries. Note that in the absence of data, we adopt the convention of fixing the same parameter value across countries in order not to bias the subsequent results and analysis. In other words, when the appropriate data exists, we let it define cross-country differences in economic structure.

Given the relationship between the gross real rate of interest and the discount rate, i.e. $(1+r)=\frac{1}{\beta}$, we use MEI data on ex-post real interest rates to imply the values of $\beta$ reported in Table 1 . Given the lack of reliable depreciation rate data, following Smets and Wouters (2003) we set the private to $10 \%$ per annum. We also applied the same rate to public capital. In all cases this contributed to producing reasonable private and public capital to 
output ratios, e.g. private: $2.15,2.50,2.57$ and public: $0.32,0.31,0.10$ for Germany, France, and the UK respectively.

To calculate the wage persistence parameter, $\eta$, we obtain real wage data from the MEI and IFS databases. We then take logs of the data and use the Kalman Filter to estimate simple AR(1) models including a fixed $\eta$ on the lagged wage and a time-varying constant term assuming that its process is $\mathrm{I}(1)$. The latter provides a rough proxy for the $M R S_{t}$ term in equation (8).

Following Kydland (1995, ch. 5, p. 134), we use data on average hours worked, $H$, to calculate the leisure weight in utility, $\mu$. We employ the simple transformation $\frac{1-h}{h}$ to calculate $\mu$, where $h=H /(7 * 14 * 52)$ is the average share of the total time endowment allocated to work and $H$ is obtained from the EO database. The normalization of $H$ to obtain $h$ follows Jorgenson (1995) and Correia, Neves and Rebelo (1995). ${ }^{9}$ Our implied leisure weights reported in Table 1 are similar in magnitude to those found in other calibration studies, see e.g. Cooley and Prescott (1995) and Chari et al. (1995) for the U.S..

The gross rates of growth of the population, $n$, and labour productivity, $z$, are calculated using IFS and ISDB data respectively. Given the lack of relevant data, we follow the study by Baier and Glomm (2001), and set the relative weight of public consumption services at $\nu=0.1$ for all countries. Finally we obtained the direct tax rates, $\tau_{0}^{y}$, from the ECFIN paper by Martinez-Mongay (2000). The rates reported in Table 1 are the weighted average of the effective tax rates on gross capital and employed labour.

\subsection{Parameters for technology and the policy rules}

In the subsequent analysis, we will consider both temporary and permanent shocks to productivity across countries. Given that the resulting volatility in macroeconomic aggregates depends on the size of the shock and the degree of persistence in the process driving technology, we normalize these parameters across countries. To understand the differential effects on volatility, we fix $\rho^{a}$ at 0.95 and shock the standard deviation of technology, $\sigma^{a}$, by 1 and $5 \%$. We then repeat this exercise when $\rho^{a}$ is fixed at unity.

We now turn to the reaction coefficients in the fiscal policy instruments (see equations $12 a, b$ ). Based on the empirical finding of Galí and Perotti (2005) and Clayes (2006) and the lack of robust estimates, we will employ a range running from 0 to 0.2 for each country. Finally the AR parameters

\footnotetext{
${ }^{9}$ The assumption is that 10 hours per day are necessary for physical needs "physiological time" and therefore do not count in the total hours available for the labor-leisure choice, i.e. the remaining 14 hours.
} 
for the effective tax rates, $\rho^{\tau}$ in $(12 d)$ were obtained using the ECFIN data. The estimates of $\rho^{\tau}$ for France, Germany and the UK respectively are: 0.944, 0.74 and 0.71 and are all significant at the $1 \%$ level.

\subsection{Watson measure}

The Watson (1993) method, used to obtain a measure of model fit below, allows us to compare characteristics of the actual data corresponding to our model with the data generated by our model. Watson points out, in the context of models which are calibrated, that it is important not to view the economic model as the data generating process, but rather as an approximation to it. The essence of Watson's approach is to determine the size of the stochastic error necessary to reconcile the model-generated covariances with the sample covariances.

To briefly illustrate the main points of the approach consider an $(n \times 1)$ vector of stationary variables $\mathbf{x}_{t}$ explained by an economic model, and its empirical counterpart $\mathbf{y}_{t}$, with covariance generating functions $\mathbf{G}_{\mathbf{x}}(z)$ and $\mathbf{G}_{\mathbf{y}}(z)$ respectively. Watson's method poses the following question, "How much error would have to be added to $\mathbf{x}_{t}$ so that the autocovariances of $\mathbf{x}_{t}+\mathbf{u}_{t}$ are equal to the autocovariances of $\mathbf{y}_{t}$ " (see Watson, 1993, p.1015). This setup implies that the difference between the model and the data can be expressed as $\mathbf{u}_{t}=\mathbf{y}_{t}-\mathbf{x}_{t}$ or $\mathbf{G}_{\mathbf{u}}(z)=\mathbf{G}_{\mathbf{y}}(z)+\mathbf{G}_{\mathbf{x}}(z)-\mathbf{G}_{\mathbf{y x}}(z)-\mathbf{G}_{\mathbf{x y}}(z)$ where $\mathbf{G}_{\mathbf{u}}(z)$ is the covariance generating function for the difference between the model and the data.

To obtain the various covariance functions requires that we (i) estimate $\mathbf{G}_{\mathbf{y}}(z)$ from the data; (ii) calculate $\mathbf{G}_{\mathbf{x}}(z)$ from the model; (iii) choose $\mathbf{G}_{\mathbf{x y}}(z)$ to minimize the variance of $\mathbf{u}_{t}$, subject to the constraint that $\mathbf{G}_{\mathbf{x y}}(z)$ is positive semi-definite. ${ }^{10}$ With these calculations in place, we can then derive Watson's RMSAE. More specifically we compute the ratio of the autospectrum of $u_{j}$ to the autospectrum of $y_{j}{ }^{11}$

$$
R_{j(\omega)}=\frac{\int_{-\pi}^{\pi} \mathbf{G}_{\mathbf{u}}(\exp (-i \omega))_{j j} d \omega}{\int_{\pi}^{\pi} \mathbf{G}_{\mathbf{y}}(\exp (-i \omega))_{j j} d \omega} .
$$

This measure is conceptually similar to the unexplained variance of a standard regression. Although it is not bounded between zero and unity, smaller values do imply a better model approximation to the data that larger

\footnotetext{
${ }^{10}$ In other words, the spectrum, $\mathbf{F}_{\mathbf{x y}}(\omega)$, is positive semidefinite.

${ }^{11}$ The spectrum is given as $\mathbf{F}(\omega)=\frac{1}{2 \pi} \mathbf{G}(\exp (-i \omega))$ (see, Hamilton, 1994, Sections 3.6, $10.3)$.
} 
ones. Finally, note that in all the results reported below, for any variable $j$, we use the entire range of the spectrum, i.e. $\left[\begin{array}{ll}-\pi & \pi\end{array}\right]{ }^{12}$

\subsection{Model Fit}

Table 2 compares the fit of our calibrated DCE model under passive policy with a baseline model under varying assumptions regarding model structure. We take the baseline RBC model (with government) is defined as a special case of our model without capital adjustment costs and real wage rigidity (i.e. $\eta=\alpha^{p}=0$ ). To understand the implications in terms of model fit, we move from this baseline to our full DCE model by adding back in the mechanisms which generate persistence and thus should have the effect of capturing some of the inertia observed in the actual data.

To obtain the measures of fit reported in Table 2, the data spectra are calculated from three $\operatorname{VAR}(1)$ models using annual data from 1970-2005. Following Watson who illustrates his method using the RBC model by King, Plosser and Rebelo (1988a, 1988b), we use consumption, investment, employment and output in the VAR. ${ }^{13}$ In addition, given the presence of public consumption and investment in our model, in the interest of parsimony, we add aggregate government expenditure (excluding transfers) to the VAR. Given our short observation period, the VAR model can be made still more parsimonious by excluding output. This is possible since we can still obtain the spectral density matrix for the data including output via the following transformation

$$
\mathbf{U}=\left(\begin{array}{cccc}
w_{c} & w_{i} & w_{g} & 0 \\
1 & 0 & 0 & 0 \\
0 & 1 & 0 & 0 \\
0 & 0 & 1 & 0 \\
0 & 0 & 0 & 1
\end{array}\right) ; \mathbf{F}_{\mathbf{y}}(\omega)=\mathbf{U F}_{c, i, g, h}(\omega) \mathbf{U}^{\prime}
$$

where $w_{c}, w_{i}$, and $w_{g}$ are the average output weights of the three expenditure components calculated from the data.

To assess the statistical significance of the fit measure, we generate 1000 replications for each model (non-parametric bootstrap). Based on these replications, we obtain the empirical distribution for the fit measure given in

\footnotetext{
${ }^{12}$ Note that this measure can also be calculated at any frequency $\omega$ or between desired ranges $\left[\omega_{1}, \omega_{2}\right]$. Since all variables are equally important when calculating the "goodness of fit" measure, we weight them equally (see, e.g. Watson 1993, p. 1018). Further details are provided in Appendix C.

${ }^{13} \mathrm{As}$ in Watson, the data (in logs) are pre-filtered using the Hodrick and Prescott (1997) filter (smoothing weight: 100).
} 
(13), which we then compare with the performance of the baseline model $\left(\eta=\alpha^{p}=0\right)$. To calculate the model spectrum including output, consumption, investment, government expenditure and hours of work from the full calibrated model spectrum (11 variables), we use a $(5 \times 11)$ selection matrix $\mathbf{E}$ with ones in the appropriate position such that $\mathbf{F}_{\mathbf{x}}(\omega)=\mathbf{E F}_{11 \times 11}(\omega) \mathbf{E}^{\prime}{ }^{14}$

\begin{tabular}{cccc}
\hline \multicolumn{4}{c}{ Table 2a: Model Fit Germany } \\
\hline \hline & $\alpha^{p}=0, \eta \neq 0$ & $\eta=0, \alpha^{p} \neq 0$ & $\alpha^{p} \neq \eta \neq 0$ \\
$\widehat{y_{t}}$ & -0.007 & 0.034 & 0.033 \\
& $(-0.014 ; 0.012)^{*}$ & $(0.019 ; 0.078)$ & $(-0.029 ; 0.090)^{*}$ \\
$\widehat{i_{t}}$ & 0.041 & 0.132 & 0.129 \\
& $(0.024 ; 0.094)$ & $(0.079 ; 0.258)$ & $(0.080 ; 0.253)$ \\
$\widehat{c_{t}}$ & 0.004 & 0.015 & 0.014 \\
& $(-0.001 ; 0.014)^{*}$ & $(0.008 ; 0.039)$ & $(0.008 ; 0.036)$ \\
$\widehat{g_{t}}$ & -0.008 & 0.056 & 0.053 \\
& $(-0.021 ; 0.026)^{*}$ & $(0.032 ; 0.122)$ & $(-0.051 ; 0.151)^{*}$ \\
$\widehat{h_{t}}$ & 0.097 & 0.746 & 0.684 \\
& $(0.085 ; 0.106)$ & $(0.675 ; 0.810)$ & $(0.616 ; 0.738)$ \\
\hline
\end{tabular}

Note that the results reported in Table 2 are in percent differences from the baseline model. Accordingly, a positive value denotes the percent improvement in fit across models and vice-versa for negative values. The numbers in parentheses are the lower and upper bounds of $5 \%$ confidence intervals. If the confidence interval includes zero, then there is not a statistically difference between that baseline model and the alternative model considered. ${ }^{15}$

\footnotetext{
${ }^{14}$ We follow Uhlig (1999) and filter the model spectrum using the power transfer function of the HP-filter with the same smoothing weight as the data.

${ }^{15}$ In Table 2 the starred results reveal that the model fit is not significantly better or worse than the baseline model. In contrast the results tagged with $\S$ indicate a significantly worse fit than the baseline model.
} 


\begin{tabular}{cccc}
\hline \multicolumn{4}{c}{ Table 2b: Model Fit France } \\
\hline \hline & $\alpha^{p}=0, \eta \neq 0$ & $\eta=0, \alpha^{p} \neq 0$ & $\alpha^{p} \neq \eta \neq 0$ \\
$\widehat{y_{t}}$ & -0.200 & 0.351 & 0.254 \\
& $(-0.314 ;-0.129)^{\S}$ & $(0.245 ; 0.555)$ & $(0.179 ; 0.402)$ \\
$\widehat{i_{t}}$ & 0.214 & 0.831 & 0.773 \\
& $(0.201 ; 0.327)$ & $(0.777 ; 0.888)$ & $(0.722 ; 0.827)$ \\
$\widehat{c_{t}}$ & 0.072 & 0.251 & 0.226 \\
& $(0.044 ; 0.156)$ & $(0.167 ; 0.446)$ & $(0.150 ; 0.402)$ \\
$\widehat{g_{t}}$ & -0.089 & 0.150 & 0.109 \\
& $(-0.178 ;-0.050)^{\S}$ & $(0.093 ; 0.304)$ & $(0.066 ; 0.224)$ \\
$\widehat{h_{t}}$ & 0.067 & 0.843 & 0.712 \\
& $(0.052 ; 0.069)$ & $(0.823 ; 0.858)$ & $(0.696 ; 0.725)$ \\
\hline \multirow{4}{c}{ Table $2 \mathrm{c}:$ Model Fit UK } \\
\hline \hline & $\alpha^{p}=0, \eta \neq 0$ & $\eta=0, \alpha^{p} \neq 0$ & $\alpha^{p} \neq \eta \neq 0$ \\
$\widehat{y_{t}}$ & 0.018 & 0.028 & 0.044 \\
& $(-0.015 ; 0.025)^{*}$ & $(0.016 ; 0.090)$ & $(0.012 ; 0.106)$ \\
$\widehat{i_{t}}$ & 0.003 & 0.011 & 0.011 \\
& $(0.002 ; 0.009)$ & $(0.006 ; 0.028)$ & $(0.006 ; 0.028)$ \\
$\widehat{c_{t}}$ & 0.001 & 0.005 & 0.004 \\
& $(0.001 ; 0.004)$ & $(0.003 ; 0.012)$ & $(0.002 ; 0.011)$ \\
$\widehat{g_{t}}$ & 0.012 & 0.019 & 0.030 \\
$\widehat{c}$ & $(-0.007 ; 0.016)^{*}$ & $(0.011 ; 0.061)$ & $(0.008 ; 0.078)$ \\
$\widehat{h_{t}}$ & 0.019 & 0.135 & 0.126 \\
& $(0.008 ; 0.072)$ & $(0.075 ; 0.324)$ & $(0.070 ; 0.308)$ \\
\hline & & &
\end{tabular}

Overall the results in Table 2 provide an interesting picture and empirical support for several of our key modelling choices. First, the presence of both real wage rigidity and capital adjustment costs improves the model fit for all countries and all variables with only two significant exceptions (for output and government spending in France when $\alpha^{p}=0$ ). Second, capital adjustment costs appear to provide greater marginal improvements in fit than real wage rigidity for all countries and for all variables. Finally, there is a significant improvement in fit for the full model for all countries and all variables with only two exceptions (output and government spending in Germany are not significantly different from the baseline). 


\section{Fiscal stabilization}

Consistent with the current debates in Europe focusing on the need and impact of countercyclical fiscal stabilization policy, we first examine the relative ability of public consumption and investment to stabilize output and debt. We will then turn to a formal welfare assessment of the volatility implications of these alternative outcomes.

\subsection{Output and debt stabilization}

The results reported in Tables 3a-c show the decrease in the variability (shown as positive numbers) of both the output and debt gaps (measured by their standard deviation) as we move from passive to active policy. In this experiment, we temporarily shock aggregate productivity by $1 \%$ (reflected by the standard deviation of productivity increasing from 0 to 0.01). We then calculate the standard deviations of the output and debt gaps under passive and active policy over 3 and 5 year horizons. Active policy here means that we switch-on one policy instrument and one policy target at a time for two different policy reaction coefficients, i.e. 0.1 and 0.2. By direct effect, we mean the effect on the policy target that the government reacts to, while by indirect, we mean the side effect on the other policy target.

For example, in Table 3a for Germany, a government consumption reaction coefficient of 0.1 to the output gap reduces the standard deviation of the latter by $24.6 \%$ over the 3 year horizon. The indirect effect of this policy on the standard deviation of the debt gap is $-25.2 \%$ meaning that, when government consumption is used to stabilize the output gap, higher debt volatility ensues. This is not unexpected since an increase in government spending raises debt requirements. When government consumption is used to react to the deviation of the current public debt-to-GDP ratio from its reference $60 \%$ rate, the corresponding fall in the standard deviation of the debt gap is only $1 \%$, while output variability rises by $2.5 \%$. In other words, stabilization of one target comes at the cost of destabilizing the other target. This applies to all the indirect effects as indicated by the negative values. Note that the indirect destabilizing effect from output to debt is stronger than the direct stabilizing effect from debt to debt. For instance, in the case we discussed above, the absolute value of $-25.2 \%$ exceeds $1 \%$. Also note that the indirect destabilizing effect from debt to output is stronger than the direct stabilizing effect from debt to debt.

We can therefore draw three broad messages from the cross-country evidence presented in Table 3: 
- First, the direct effect of fiscal intervention is stabilizing but the indirect effect is destabilizing with respect to the chosen targets. Thus, there is a trade-off. The effects of reaction to the output gap are much bigger in magnitude than the effects of reaction to the debt gap. Specifically, when policymakers counter-cyclically respond to the output gap, there are big stabilizing effects on output as well as big destabilizing effects on debt. When policymakers counter-cyclically respond to the debt gap, there are small stabilizing effects on debt and small destabilizing effects on output, where the latter exceed the former.

- Second, the direct stabilizing effects are higher in France than in Germany and the UK, due to higher real wage rigidity in France.

- Third, the stabilizing effects of public consumption are stronger than those of public investment. One reason is simply that the former is a much larger share of GDP than the latter so that, either as an automatic stabilizer or as an instrument of active policy, it has a bigger impact. Also, when the aim is stabilization, it seems it is better to use policy instruments (like government consumption) that do not directly affect the supply side of the economy. All this provides support for the argument that public finance stabilization should take place via reductions in government consumption.

\begin{tabular}{|c|c|c|c|c|}
\hline \multicolumn{5}{|c|}{ Table 3a: Output and debt stabilization: Germany } \\
\hline react. coef. & 0.1 & 0.2 & 0.1 & 0.2 \\
\hline & \multicolumn{4}{|c|}{ 3-yr direct } \\
\hline pub. cons. & 0.246 & 0.384 & 0.010 & 0.005 \\
\hline pub. invst. & 0.101 & 0.186 & 0.004 & 0.008 \\
\hline & \multicolumn{4}{|c|}{3 -yr indirect } \\
\hline pub. cons. & -0.025 & -0.038 & -0.252 & -0.511 \\
\hline pub. invst. & -0.010 & -0.019 & -0.090 & -0.180 \\
\hline & \multicolumn{4}{|c|}{5 -yr direct } \\
\hline pub. cons. & 0.146 & 0.242 & 0.004 & -0.008 \\
\hline pub. invs. & 0.060 & 0.111 & 0.002 & 0.002 \\
\hline & \multicolumn{4}{|c|}{5 -yr indirect } \\
\hline pub. invs. & -0.015 & -0.022 & -0.237 & -0.477 \\
\hline pub. cons. & -0.006 & -0.012 & -0.084 & -0.168 \\
\hline
\end{tabular}




\begin{tabular}{|c|c|c|c|c|}
\hline \multicolumn{5}{|c|}{ Table 3b: 0utput and debt stabilization: France } \\
\hline react. coef. & 0.1 & 0.2 & 0.1 & 0.2 \\
\hline & \multicolumn{4}{|c|}{ 3-yr direct } \\
\hline pub. cons. & 0.376 & 0.283 & 0.013 & 0.015 \\
\hline \multirow[t]{2}{*}{ pub. invst. } & 0.199 & 0.330 & 0.006 & 0.011 \\
\hline & \multicolumn{4}{|c|}{ 3-yr indirect } \\
\hline pub. cons. & -0.046 & -0.072 & -0.196 & -0.418 \\
\hline \multirow[t]{2}{*}{ pub. invst. } & -0.018 & -0.036 & -0.073 & -0.150 \\
\hline & \multicolumn{4}{|c|}{5 -yr direct } \\
\hline pub. cons. & 0.248 & 0.347 & 0.006 & 0.001 \\
\hline \multirow[t]{2}{*}{ pub. invs. } & 0.115 & 0.204 & 0.003 & 0.005 \\
\hline & \multicolumn{4}{|c|}{5 -yr indirect } \\
\hline pub. cons. & -0.025 & -0.040 & -0.183 & -0.385 \\
\hline pub. invs. & -0.010 & -0.020 & -0.068 & -0.139 \\
\hline \multicolumn{5}{|c|}{ Table 3c: 0utput and debt stabilization: UK } \\
\hline & \multicolumn{2}{|c|}{$\%$ ch. $\sigma\left(\widehat{y}_{t}\right)$} & \multicolumn{2}{|c|}{$\%$ ch. $\sigma\left(\widehat{b}_{t}\right)$} \\
\hline \multirow[t]{2}{*}{ react. coef. } & 0.1 & 0.2 & 0.1 & 0.2 \\
\hline & \multicolumn{4}{|c|}{ 3-yr direct } \\
\hline pub. cons. & 0.174 & 0.300 & 0.006 & 0.006 \\
\hline \multirow[t]{2}{*}{ pub. invst. } & 0.040 & 0.077 & 0.001 & 0.003 \\
\hline & \multicolumn{4}{|c|}{3 -yr indirect } \\
\hline pub. cons. & -0.014 & -0.024 & -0.169 & -0.341 \\
\hline \multirow[t]{2}{*}{ pub. invst. } & -0.003 & -0.006 & -0.035 & -0.069 \\
\hline & \multicolumn{4}{|c|}{5 -yr direct } \\
\hline pub. cons. & 0.102 & 0.180 & 0.002 & -0.002 \\
\hline \multirow[t]{2}{*}{ pub. invs. } & 0.023 & 0.045 & 0.001 & 0.001 \\
\hline & \multicolumn{4}{|c|}{ 5-yr indirect } \\
\hline pub. cons. & -0.008 & -0.014 & -0.160 & -0.321 \\
\hline pub. invs. & -0.002 & -0.004 & -0.033 & -0.065 \\
\hline
\end{tabular}

\subsection{Welfare analysis}

Following Rotemberg and Woodford (1997) and Woodford (2003), we now turn to a formal welfare ranking of the two policy regimes (i.e. passive versus active) to determine whether policymakers should act or not and, if so, by how much and to which state variable. To carry out this analysis, we first solve for a compensating consumption supplement that makes welfare equal in the two policy regimes (see, e.g. Lucas (1990)). The value of this 
supplement will provide us with a measure of the welfare difference between the two policy regimes expressed as a share of consumption. To calculate this measure requires a measure of aggregate utility under the various states considered (see Appendix D for a full derivation). With these in place, we can then subject the model to a series of stochastic productivity shocks (i.e. 1000 per experiment) to understand the quantitative welfare implications of moving from passive to active fiscal policy. In light of either the necessary condition for fiscal solvency or Tinbergen's rule, we evaluate one instrument and one target at a time.

\subsubsection{Compensating consumption supplement}

Let $W^{p}$ denote the intertemporal expected discounted lifetime utility that the household enjoys under passive policy, and $W^{a}$ denote the same under active policy. Equations (1) and (2) imply (see D.1 in Appendix D)

$$
W^{j} \equiv E_{0} \sum_{t=0}^{\infty} \beta^{t}\left[\ln c_{t}^{j}+\mu \ln \left(1-h_{t}^{j}\right)+\nu \ln \left(g_{t}^{c, j}\right)+(1+\nu) \ln Z_{t}\right]
$$

where the superscripts $j=p, a$ denote passive and active policy respectively.

Working as in Lucas (1990), we next let $\xi c_{t}^{p}$ denote a compensating consumption supplement at each date under the active policy regime that is proportional by $\xi$ to private consumption under the passive reference regime and makes $W^{a}=W^{p}$. Thus,

$$
W^{a}=E_{0} \sum_{t=0}^{\infty} \beta^{t}\left[\ln \left\{(1+\xi) c_{t}^{p}\right\}+\mu \ln \left(1-h_{t}^{p}\right)+\nu \ln \left(g_{t}^{c, p}\right)+(1+\nu) \ln Z_{t}\right] .
$$

The difference between welfare in the active and passive cases is then given by:

$$
W^{a}-W^{p}=(1+\xi) \sum_{t=0}^{\infty} \beta^{t}=\frac{\ln (1+\xi)}{(1-\beta)}
$$

or

$$
\xi=\left[e^{(1-\beta)\left(W_{t}^{a}-W_{t}^{p}\right)}-1\right] \times 100 .
$$

Therefore, if $\xi>0$, there is a welfare gain of moving from passive to active policy and vice versa for $\xi<0$. 


\subsubsection{Aggregate welfare}

To obtain estimates of $W^{a}$ and $W^{p}$ and hence $\xi$, we start by deriving the second-order approximation of the within-period aggregate utility, the model's constraints, and in turn the lifetime expected utility. However, equation (D.10) in Appendix D shows that this second-order approximation contains linear deviations terms. ${ }^{16}$ The presence of these terms implies that a secondorder approximation to expected utility is not consistent with a first-order one to the equilibrium solution of the endogenous variables in Appendix B (see e.g. Woodford (2003) pp. 383-7). In other words, since we have used a linear approximation to the model, we need an approximation to expected utility that is purely quadratic.

Following Rotemberg and Woodford (1997) and Woodford (2003, ch. 6), we derive a quadratic approximation to expected utility that includes no linear terms of this kind by ensuring that the long-run equilibrium around which we have approximated is socially optimal, i.e. it reproduces the real allocations of the social planner in the long run. As we show in Appendix D, this effectively eliminates the problematic linear terms in the approximate welfare function. In other words, we derive a set of policy rules for our longrun DCE economy so as the latter's allocations mimic those of the social planner. A comparison of the long-run social planner's solution with the longrun DCE solution reveals that this can happen when the size of the output subsidy offsets the distortion resulting from the income tax (see Appendix $\mathrm{D}$ and in particular equation (D.28a)). It is important to point out that, in the long run of our economy, distortions arise only from the side of policy and the use of income taxes in particular. ${ }^{17}$ We therefore find it natural to undo the (income tax) policy distortion by appropriately using another policy instrument. ${ }^{18}$

Based on the above, we will assess the welfare implications of passive

\footnotetext{
${ }^{16}$ More specifically, the linear terms are in hours worked, government consumption and the two capital stocks.

${ }^{17}$ Note that due to the wage setting equation (8), there are no distortions from the market side in the long run.

${ }^{18}$ The same procedure has been used in various forms by Rotemberg and Woodford (1997) and more recently Leith and Wren-Lewis (2006) who use the output subsidy to undo the distortion resulting from monopolistic power in the long run. An alternative way of attaining an approximation, if one wants to work with a distorted long run, is to solve for a second-order approximation to the complete system of the endogenous variables and then use this solution to evaluate a quadratic approximation to expected utility. Yet another alternative is to use a second-order approximation to the aggregate supply relationship only to eliminate the linear terms in the second-order approximate welfare measure (see, e.g Benigno and Woodford (2004) for a review of alternative methods). Here we prefer to keep the convenience of a linear-quadratic setup for the comparison of policy regimes.
} 
versus active $(j=p, a)$ fiscal policy using the following quadratic welfare function (see equation (D.29) in Appendix 4)

$$
\begin{aligned}
& E_{0}\left[\sum_{t=0}^{\infty} \beta^{t} U_{t}^{j, s}\right] \\
\simeq & \text { t.i.p. }+E_{0}\left[\sum _ { t = 0 } ^ { \infty } \beta ^ { t } \left(a_{5}^{*}\left(\widehat{k}_{t+1}^{j}-\widehat{k}_{t}^{j}\right)^{2}+a_{6}^{*}\left(\widehat{k}_{t+1}^{g, j}-\widehat{k}_{t}^{g, j}\right)^{2}-a_{7}^{*}\left(\widehat{c}_{t}^{j}\right)^{2}\right.\right. \\
& \left.\left.-a_{8}^{*}\left(\widehat{i}_{t}^{j}\right)^{2}-a_{9}^{*}\left(\widehat{g}_{t}^{c, j}\right)^{2}-a_{10}^{*}\left(\widehat{g}_{t}^{i, j}\right)^{2}+a_{11}^{*}\left(\widehat{y}_{t}^{j}\right)^{2}-a_{12}^{*}\left(\widehat{h}_{t}^{j}\right)^{2}\right)\right]
\end{aligned}
$$

where the $s$ superscript denotes the second-order approximation to utility and t.i.p. denotes the terms independent of policy, e.g.

$$
\begin{aligned}
& \text { t.i.p. } \equiv \frac{U}{1-\beta}+a_{1}^{*} \widehat{k}_{0}+a_{2}^{*} \widehat{k}_{0}^{g}+\sum_{t=0}^{\infty} \beta^{t}\left[a_{3}^{*} \widehat{Z}_{t}+a_{4}^{*} \widehat{a}_{t}\right] \\
& a_{1}^{*}=\frac{n z k^{*}}{c^{*} \beta}, \quad a_{2}^{*}=\frac{n z k^{g *}}{c^{*} \beta}, \quad a_{3}^{*}=1+\nu, \quad a_{4}^{*}=\frac{y^{*}}{c^{*}}, \\
& a_{5}^{*}=\frac{n z\left(1-\delta^{p}\right) k^{2 *}}{2 c^{*} i^{*}}, \quad a_{6}^{*}=\frac{n z\left(1-\delta^{g}\right)\left(k^{g *}\right)^{2}}{2 c^{*} g^{i *}}, \quad a_{7}^{*}=\frac{1}{2}, \quad a_{8}^{*}=\frac{i^{*}}{2 c^{*}}, \\
& a_{9}^{*}=\frac{g^{c *}}{2 c^{*}}, \quad a_{10}^{*}=\frac{g^{2 *}}{2 c^{*}}, \quad a_{11}^{*}=\frac{y^{*}}{2 c^{*}}, \quad a_{12}^{*}=\frac{\mu h^{*}}{2\left(1-h^{*}\right)^{2}} .
\end{aligned}
$$

and a $*$ superscript on the steady-state endogenous variables denotes the DCE solution that replicates the social planner's. ${ }^{19}$

It is worth noting that, in contrast to Woodford (2003)-type research, due to the presence of private and public capital accumulation in our model, the welfare function given by (16) appears to depend both positively and

\begin{tabular}{|c|c|c|}
\hline \multicolumn{3}{|c|}{ Table 4: Net Variance (passive case } \\
\hline$\overline{\sigma^{2}}$ & 0.01 & 0.05 \\
\hline Germany & -0.0003 & -0.0074 \\
\hline France & -0.0005 & -0.0135 \\
\hline UK & -0.0002 & -0.0040 \\
\hline
\end{tabular}
negatively on the variances of the relevant variables. The net effect of these competing effects should clearly be negative in the passive case. While (16) is too complicated to sign analytically, the results in Table 4 provide numeric evidence which shows that an increase in uncertainty (reflected by $\sigma^{2}$ increasing from 0 to 0.01 and from 0.01 to 0.05 ) leads to the expected rise in the net variance and hence a fall in aggregate welfare. ${ }^{20}$

\footnotetext{
${ }^{19}$ Following the literature we calculate discounted lifetime utility over a 400 year horizon here.

${ }^{20}$ As above, we calculate discounted lifetime utility over 400 years and shock productivity 1000 times. Also we do not include the t.i.p terms in these calculations.
} 


\subsubsection{General Equilibrium Welfare (active versus passive policy)}

Figures 1 and 2 are calculated for productivity shocks of $1 \%$ and $5 \%$ respectively. ${ }^{21}$ Before more detailed discussion below, the following two observations from these Figures are noteworthy:

- First, even when there are substantial differences in the standard deviation of output between active and passive policy as evidenced in Table 3 , these differences are translated into small differences in general equilibrium welfare. ${ }^{22}$ This finding applies across policy instruments, size, and duration of the shocks.

- Second, consistent with the positive results of Table 3, counter-cyclical responses via government consumption have bigger welfare implications than similar responses via government investment.

\section{[Figures 1-2 about here]}

Some possible explanations of the first point include: (i) stabilization of output via the counter-cyclical use/response of policy instruments unavoidably increases the volatility of the latter, and this mitigates the welfare gains from active policy in general equilibrium; (ii) as shown in Table 3, debt stabilization comes at the cost of output volatility and this is bad for welfare, see e.g. the second row of the figures for Germany and the UK. ${ }^{23}$

Keeping in mind the above observations, let us now consider the welfare implications of counter-cyclical policy when the economy is hit by a $1 \%$ permanent productivity shock. We start with a counter-cyclical reaction to

\footnotetext{
${ }^{21}$ Given that the effects of temporary shocks are qualitatively similar to the permanent case but smaller, depending on the size of the AR coefficient, they are not reported here but are available on request.

${ }^{22}$ Although the welfare differences are small, they appear consistent with the findings of other studies. For instance, when Lucas (1990) uses the same measure of welfare as in equation (15) above, he finds the welfare gain (of moving from the existing tax structure in the US to a Ramsey structure with zero capital income taxation) to be around 1-2 percent of consumption. Here, our welfare difference between active and passive (say third- to second-best) is clearly much smaller. On the other hand, the difference between active and passive policy should be expected to be far less dramatic than the difference between the two tax structures (say second- to first-best) compared by Lucas (i.e. from $36 \%$ to $0 \%$ tax rates). It also appears that our use of an log-linear utility function is not expected to produce an overly strong downward bias in size of the welfare effects. For example, Chari et al. (1994) report: "For the model with log utility, the welfare gains (from a switch to zero Ramsey tax rate) are $1 \%$ of consumption; for the model with high risk aversion, the gains are $1.3 \% "$.

${ }^{23}$ We will return to the explanation for France below.
} 
the output gap. The first row of Figure 1 reveals that there are small benefits from active policy in Germany and the UK, while output stabilization reduces welfare for France. Thus, the policy lesson is "Do not intervene to stabilize the output gap when real wage rigidity is high. When real wage rigidity is low, there are small benefits from output stabilization".

We continue with counter-cyclical reaction to the debt target. Inspection of the second row of Figure 1 reveals that there are very small welfare losses in Germany and practically zero effects in the UK, while France clearly benefits from debt stabilization. Thus, the policy lesson is "Intervene to stabilize the public debt when real wage rigidity is high. When real wage rigidity is low, welfare differences are negligible". To understand this result, recall from Table 3 that debt stabilization can be achieved at the cost of higher output volatility, where the latter destabilizing effect exceeds the former stabilizing one. In other words, in the second row of Figure 1, when debt is stabilized and hence output is destabilized, France benefits. This is then consistent with the results from the first row of Figure 1; namely, output stabilization hurts France, while it is beneficial for Germany and the UK.

We can now combine results. In an economy with a relatively flexible (resp. sclerotic) labour market, policy intervention that reduces output fluctuations is a qualitatively good (resp. bad) idea. In other words, when real wage rigidity is relatively low, counter-cyclical output stabilizing policy plays its expected, welfare-enhancing role. On the other hand, the same policy hurts the aggregate economy when real wage rigidity is relatively high (as in France). To understand this seemingly paradoxical result recall that real wage rigidity means that current allocations and prices depend myopically on their lagged values. When this dependence is high, so that the current state of the economy matters little, it is not a good idea to absorb output fluctuations by varying the policy instruments. This simply deteriorates the myopic dependence on the past. In other words, in a sclerotic economy, exposing the economy to the current cyclical real situation is welfare enhancing. Following this logic, reaction to a public debt target is welfare deteriorating (resp. beneficial) for countries with relatively flexible (resp. sclerotic) labour markers. This is because debt stabilization comes at the cost of higher output volatility; the latter is good only for countries with relatively rigid labour markets.

\section{Conclusions}

In this paper, we developed a DSGE model to examine the quantitative macroeconomic implications of counter-cyclical fiscal policy in the EU-3. In 
our model setup we: (i) allow fiscal policy instruments to react to two key fundamentals, i.e. output and public debt; (ii) justify feedback policy by assuming real wage rigidity, which is widely believed to be one of the main scleroses in Europe; (iii) deliberately employ a minimal setup where the only distorting effect from the part of policy is non-availability of lump-sum policy instruments; ${ }^{24}$ (iv) study how each fiscal policy instrument, as well as the choice between an output gap target and a public finance target, (de)stabilize the economy, where by stabilization we mean both the internal stability of the system and the standard deviation of macroeconomic variables when the economy is subjected to supply shocks; (v) calculate the general equilibrium welfare difference when moving from passive to active policy for each policy instrument and each target.

Our findings revealed that our model was a better approximation of the data than a standard baseline RBC model and that, in general, a model with real wage rigidity fits better. We then used our model to investigate whether active policy is better than passive policy in terms of the standard deviation of output and public debt, as well as in terms of general equilibrium welfare.

While the exact quantitative answer depends on what policymakers target, the policy instrument they use, and the degree of real wage rigidity, there is a robust result: the general equilibrium welfare gains (if any) from active policy are negligible quantitatively. Accordingly, the simply message arising from our welfare analysis is that much of the recent enthusiasm in Europe for fiscal stabilization policy appears to be misplaced.

\section{References}

[1] Aloi, M., T. Lloyd-Braga and H. Whitta-Jacobsen (2003) "Endogenous business cycles and systematic stabilization policy", International Economic Review, 44: 895-915.

[2] Andrés, J. and R. Domenech (2006) "Automatic stabilizers, fiscal rules and macroeconomic stability", European Economic Review, 50: 14871506

\footnotetext{
${ }^{24}$ In other words, we ignore many of the other well known problems associated with the conduct of fiscal policy (e.g. time lags, administrative costs, time inconsistency of chosen policies, non-benevolent motives like staying in power, etc.). See e.g. Malley et al. (2006) for inefficiencies associated with electoral competition and uncertainty in a DSGE model for the US. See also e.g. Park and Philippopoulos (2003) for inefficiencies associated with redistributive transfers in a theoretical GE model.
} 
[3] Baier, S. and G. Glomm (2001) "Long-run growth and welfare effects of public policies with distortionary taxation", Journal of Economic Dynamics and Control, 25: 2007-2042.

[4] Baxter, M. and R. King (1993) "Fiscal policy in general equilibrium" American Economic Review, 83: 315-334.

[5] Benigno P. and M. Woodford (2004) "Inflation stabilization and welfare: The case of a distorted steady state", NBER Working Paper, no. 10838.

[6] Blanchard and Galí (2005) "Real Wage Rigidities and the New Keynesian Model", NBER Working Papers, no. 11806.

[7] Canova, F., and G. De Nicoló (2002) "Monetary disturbances matter for business fluctuations in the G-7", Journal of Monetary Economics, 49, 1131-1159.

[8] CESifo Economic Studies Special Issue (2005) "The revival of aggregate demand policies: back to Keynes", R. Beetsma, R. and G. Illing (eds), vol. 51 , no. 4 .

[9] Chari V., Christiano, L. and P. Kehoe (1995) "Policy analysis in business cycle models, in Frontiers of Business Cycle Research", edited by T. Cooley. Princeton University Press, Princeton.

[10] Christiano L. and S. Harrison (1999) "Chaos, sunspots and automatic stabilizers", Journal of Monetary Economics, 44: 3-31.

[11] Claeys, P. (2006), "Policy mix and debt sustainability: evidence from fiscal rules", Empirica, 33: 89-112.

[12] Cooley,T. and E. Prescott (1995) "Economic Growth and Business Cycles in Frontiers of Business Cycle Research", edited by T. Cooley. Princeton University Press, Princeton.

[13] Cooper, R. and J. Haltiwanger (2002) "On the nature of capital adjustment costs," mimeo; previously NBER Working Paper No. 7925, 2000.

[14] Correia, I., Neves, J., and S.Rebelo (1995) "Business cycles in a small open economy", European Economic Review, 39, 1089-1113.

[15] Edge, R. (2003) "A Utility-Based Welfare Criterion in a Model with Endogenous Capital Accumulation", Federal Reserve Board Finance and Economics Discussion Series, 2003-66. 
[16] Galí, J. (2005) "Modern perspectives on fiscal stabilization policies", CESifo Economic Studies, 51: 587-599.

[17] Galí, J. and R. Perotti (2005) "Fiscal policy and monetary integration in Europe", Economic Policy, 535-572.

[18] Guo J. and K. Lansing (1998) "Indeterminacy and stabilization policy", Journal of Economic Theory, 82, 481-490.

[19] Hamilton, J. (1994), Time Series Analysis, Princeton University Press, Princeton, New Jersey.

[20] Heer, B. and A. Maussner (2005) Dynamic General Equilibrium Modelling, Computational Methods and Applications, Springer: Berlin.

[21] Jorgenson (1995), Productivity: International comparisons of economic growth, MIT Press, Cambridge Massachusetts.

[22] King R. and S. Rebelo (1999) "Resuscitating real business cycles", in Handbook of Macroeconomics, vol. 1B, edited by J. Taylor and M. Woodford, North Holland.

[23] King, R. G., Plosser, C. I. and Rebelo, S. T. (1988a), "Production, Growth and Business Cycles, I. The Basic Neoclassical Model", Journal of Monetary Economics, 21, 195-232.

[24] King, R. G., Plosser, C. I. and Rebelo, S. T. (1988b), "Production, Growth and Business Cycles, II. New Directions", Journal of Monetary Economics, 21, 309-341.

[25] Klein, P. (2000), "Using the generalized Schur form to solve a multivariate linear rational expectations model" Journal of Economic Dynamics and Control 24, 1405-1423.

[26] Kydland, F. (1995) "Business cycles and aggregate labor market fluctuations", edited by T. Cooley. Princeton University Press, Princeton.

[27] Lansing, K. (1998) "Optimal fiscal policy in a business cycle model with public capital" Canadian Journal of Economics, 31: 337-364.

[28] Leith. C. and S. Wren-Lewis (2006), "Fiscal Sustainability in a New Keynesian Model", University of Glasgow Discussion Paper in Economics, 200611. 
[29] Lucas, R. (1990) "Supply-side economics: an analytical review" Oxford Economic Papers, 42: 293-316.

[30] Malley, J., Philippopoulos, A. and U. Woitek (2007), Electoral uncertainty, fiscal policy and macroeconomic fluctuations, Journal of Economic Dynamics and Control (In Press).

[31] Martinez-Mongay, C. (2000), ECFIN's effective tax rates. Properties and comparisons with other tax indicators, DG ECFIN Economic Papers, No 146, Brussels: European Commission.

[32] Park H. and A. Philippopoulos A. (2003) "On the dynamics of growth and fiscal policy with redistributive transfers" Journal of Public Economics, 87: 515-538.

[33] Priestley, M. (1981) "Spectral Analysis and Times Series" Academic Press.

[34] Rotemberg J.J. and M. Woodford (1997) "An optimization-based econometric framework for the evaluation of monetary policy, in B.S.Bernanke and J.J. Rotemberg (eds), NBER Macroeconomic Annual, Cambridge, Mass.

[35] Smets, F. and R. Wouters (2003) "An estimated dynamic stochastic general equilibrium model of the Euro Area", Journal of the European Economic Association, 1(5): 1123-1175.

[36] Tanzi V. (2005) "Fiscal policy and fiscal rules in the EU, CESifo Forum, $3 / 2005,57-64$.

[37] Uhlig, H. (1999) "A toolkit for analyzing nonlinear dynamic stochastic models easily" in Computational Methods for the Study of Dynamic Economies (ed) Marimon, R. and A. Scott, Oxford University Press.

[38] Watson, M. (1993) "Measures of fit for calibrated Models" Journal of Political Economy, 101(6): 1011-1041.

[39] Woodford, M. (2003) "Interest and Prices" Princeton University Press. 


\section{Appendices}

\subsection{Appendix A: Steady-state of DCE}

In the absence of technology shocks, i.e. $\varepsilon_{t}=0$ for all $t$, the economy (see section 2.5.1) converges to its steady-state in which all of the stationary variables are constant. In other words, for any $x_{t}, x$ denotes its long-run value. This implies that $a=a_{0}, g^{c}=g_{0}^{c} y, g^{i}=g_{0}^{i} y, g^{t}=g_{0}^{t} y, \tau^{y}=\tau_{0}^{y}$, $\partial I_{t} / \partial K_{t+1}=1$ and $\partial I_{t+1} / \partial K_{t+1}=\left(\delta^{p}-1\right)$. Accordingly, expressions for the model consistent long-run values, $\left(h, y, c, i, k, k^{g}, b, r^{k}, w, r^{b}\right)$, comprised of non-linear convolutions of the underlying structural parameters, are given by:

$$
\begin{gathered}
h=\frac{\omega_{1} \omega_{2}}{\mu+\omega_{1} \omega_{2}} \\
y=\left[a_{0}\left(\frac{\alpha_{1} \beta\left(1-\tau_{0}^{y}\right)\left(1-\tau_{0}^{s}\right)}{n z-\beta\left(1-\delta^{p}\right)}\right)^{\alpha_{1}} h^{\alpha_{2}}\left(\frac{g_{0}^{i}}{n z+\delta^{g}-1}\right)^{1-\alpha_{1}-\alpha_{2}}\right]^{1 / \alpha_{2}} \\
c=\omega_{2}^{-1} y \\
i=\left(n z+\delta^{p}-1\right)\left(\frac{\alpha_{1} \beta\left(1-\tau_{0}^{y}\right)\left(1-\tau_{0}^{s}\right)}{n z-\beta\left(1-\delta^{p}\right)}\right) y \\
k=\left(\frac{\alpha_{1} \beta\left(1-\tau_{0}^{y}\right)\left(1-\tau_{0}^{s}\right)}{n z-\beta\left(1-\delta^{p}\right)}\right) y \\
k^{g}=\left(\frac{g_{0}^{i}}{n z+\delta^{g}-1}\right) y \\
b=\omega_{3} y \\
r^{k}=\frac{\alpha_{1}\left(1-\tau_{0}^{s}\right) y}{k} \\
w=\frac{\alpha_{2}\left(1-\tau_{0}^{s}\right) y}{h} \\
r^{b}=\frac{n z-\beta}{\beta\left(1-\tau_{0}^{y}\right)}
\end{gathered}
$$

where,

$$
\begin{gathered}
\omega_{1} \equiv \alpha_{2}\left(1-\tau_{0}^{y}\right)\left(1-\tau_{0}^{s}\right) \\
\omega_{2} \equiv \frac{n z-\beta\left(1-\delta^{p}\right)}{\left[n z-\beta\left(1-\delta^{p}\right)\right]\left(1-g_{0}^{c}-g_{0}^{i}\right)-\left(n z+\delta^{p}-1\right) \alpha_{1} \beta\left(1-\tau_{0}^{y}\right)\left(1-\tau_{0}^{s}\right)} \\
\omega_{3} \equiv \frac{g_{0}^{c}+g_{0}^{i}+g_{0}^{t}-\tau_{0}^{y}-\tau_{0}^{s}}{n z\left(1-\beta^{-1}\right)}
\end{gathered}
$$


Given that we will employ data for two EMU member countries, we will explicitly consider the case where according to the implicit rules of the Stability and Growth Pact, steady-state public debt is $60 \%$ of output. In this circumstance, instead of $(A .7)$ we set $b=0.6(y)$. This then implies that one of the other policy instruments has to become endogenous in the longrun to satisfy the government budget constraint. If we choose, for example, to residually determine government transfers, then its steady-state value is given by

$$
g_{0}^{t}=0.6(n z)\left(1-\beta^{-1}\right)-g_{0}^{c}-g_{0}^{i}+\tau_{0}^{y}+\tau_{0}^{s} .
$$

\subsection{Appendix B: First-order approximation of DCE}

To be in a position to solve the model, we take the first-order Taylor series expansion of the stationary $D S G E$ in section 2.5 around the steady-state derived in Appendix A to obtain

$$
\begin{aligned}
& \widehat{y}_{t}=\widehat{a}_{t}+\alpha_{1} \widehat{k}_{t}+\alpha_{2} \widehat{h}_{t}+\left(1-\alpha_{1}-\alpha_{2}\right) \widehat{k}_{t}^{g} \\
& \widehat{y}_{t}=\frac{c}{y} \widehat{c}_{t}+\frac{i}{y} \widehat{i}_{t}+g_{0}^{c} \widehat{g}_{t}^{c}+g_{0}^{i} \widehat{g}_{t}^{i} \\
& n z \widehat{k}_{t+1}=\left(1-\delta^{p}\right) \widehat{k}_{t}+\frac{i}{k} \widehat{i}_{t} \\
& \widehat{w}_{t}=\eta \widehat{w}_{t-1}+(1-\eta)\left\{\widehat{c}_{t}+\left(\frac{h}{1-h}\right) \widehat{h}_{t}+\left(\frac{\tau_{0}^{y}}{1-\tau_{0}^{y}}\right) \widehat{\tau}_{t}^{y}\right\} \\
& E_{t} \widehat{c}_{t+1}-\widehat{c}_{t}=\beta(n z)^{-1}\left\{\left[n z \beta^{-1}+\delta^{p}-1\right]\left(E_{t} \widehat{r}_{t+1}^{k}-\left(\frac{\tau_{0}^{y}}{1-\tau_{0}^{y}}\right) E_{t} \widehat{\tau}_{t+1}^{y}\right)\right. \\
& -\alpha^{p}\left[n z+\delta^{p}-1\right]\left[n z \beta^{-1}\left(\widehat{i}_{t}-\widehat{k}_{t}\right)-\left(1-\delta^{p}+\frac{i}{k}\right)\right. \\
& \left.\left.\left(E_{t} \widehat{i}_{t+1}-\widehat{k}_{t+1}\right)\right]\right\} \\
& n z \widehat{k}_{t+1}^{g}=\left(1-\delta^{g}\right) \widehat{k}_{t}^{g}+g_{0}^{i} \frac{y}{k^{g}} \widehat{g}_{t}^{i} \\
& g_{0}^{c} \widehat{g}_{t}^{c}+g_{0}^{i} \widehat{g}_{t}^{i}+g_{0}^{t} \widehat{g}_{t}^{t}+\frac{n z}{\beta} \frac{b}{y} \widehat{b}_{t}+\left(1-\tau_{0}^{y}\right) r^{b} \frac{b}{y} \widehat{r}_{t}^{b} \\
& =n z \frac{b}{y} \widehat{b}_{t+1}+\tau_{0}^{y}\left(1+r^{b} \frac{b}{y}\right) \widehat{\tau}_{t}^{y}+\left(\tau_{0}^{y}+\tau_{0}^{s}\right) \widehat{y}_{t} \\
& E_{t} \widehat{r}_{t+1}^{k}=E_{t} \widehat{y}_{t+1}-\widehat{k}_{t+1}
\end{aligned}
$$




$$
\begin{aligned}
& {\left[n z \beta^{-1}-1\right] E_{t} \widehat{r}_{t+1}^{b}=} {\left[n z \beta^{-1}+\delta^{p}-1\right] E_{t} \widehat{r}_{t+1}^{k} } \\
&-\left(\frac{\delta^{p} \tau_{0}^{y}}{1-\tau_{0}^{y}}\right) E_{t} \widehat{\tau}_{t+1}^{y}-\alpha^{p}\left[n z+\delta^{p}-1\right] \\
&\left(n z \beta^{-1}\left(\widehat{i}_{t}-\widehat{k}_{t}\right)-\left(1-\delta^{p}+\frac{i}{k}\right)\left(E_{t} \widehat{i}_{t+1}-\widehat{k}_{t+1}\right)\right) \\
& \widehat{w}_{t}=\widehat{y}_{t}-\widehat{h}_{t}
\end{aligned}
$$

where for any variable $x_{t}, \widehat{x}_{t}=\ln \left(x_{t} / x\right) ; x$ is the model-consistent longrun value of $x_{t}$ defined in sub-section $6.1 .^{25}$ In other words the linearized expressions given by $(B .1-B .10)$ represent (i) the production function; (ii) the aggregate expenditure identity; (iii) private investment; (iv) the condition for employment; (v) the Euler-equation for private capital; (vi) public capital; (vii) the government budget constraint; (viii) the return to private capital; (ix) the Euler-equation for bonds and (x) the return to labor.

Log-linearizing the stationary laws of motion for the fiscal policy instruments discussed in Section 2.6 around the steady-state derived in Appendix A yields

$$
\begin{gathered}
\widehat{g}_{t}^{c}=\left(1+\gamma_{y}^{g}-\gamma_{b}^{g}\right) \widehat{y}_{t}+\gamma_{b}^{g} \widehat{b}_{t} \\
\widehat{g}_{t}^{i}=\left(1+\gamma_{y}^{i}-\gamma_{b}^{i}\right) \widehat{y}_{t}+\gamma_{b}^{i} \widehat{b}_{t} \\
\widehat{g}_{t}^{t}=\widehat{y}_{t} \\
\widehat{\tau}_{t}^{y}=\rho^{\tau} \widehat{\tau}_{t-1}^{y}
\end{gathered}
$$

Finally the log-linearized process for technology is given by

$$
\widehat{a}_{t}=\rho^{a} \widehat{a}_{t-1}+\varepsilon_{t}
$$

\subsection{Appendix C: Model solution and Watson's mea- sure}

\subsubsection{Model solution}

To solve $(B 1)-(B 10)$, we first substitute for $(B 11-B 13)$ and then rewrite the system in matrix form ${ }^{26}$ to obtain

$$
\mathbf{C}_{z} \mathbf{z}_{t}=\mathbf{C}_{y \lambda}\left(\begin{array}{c}
\mathbf{y}_{t} \\
\lambda_{t}
\end{array}\right)+\mathbf{C}_{x} \mathbf{x}_{t}
$$

\footnotetext{
${ }^{25}$ Note that $\widehat{r}_{t}^{b}=\ln \left[\left(1+\widehat{r}_{t}^{b}\right) / r^{b}\right]$.

${ }^{26}$ The following discussion and notation draws on Heer and Maussner (2005, Ch. 2) and Klein (2000). The programs used to solve the model and to calculate the Watson measure were written from first principles in Matlab Version 7, Release 14.
} 


$$
\begin{gathered}
\mathbf{D}_{y \lambda}\left(\begin{array}{c}
E_{t}\left[\mathbf{y}_{t+1}\right] \\
E_{t}\left[\boldsymbol{\lambda}_{t+1}\right]
\end{array}\right)+\mathbf{F}_{y \lambda}\left(\begin{array}{c}
\mathbf{y}_{t} \\
\boldsymbol{\lambda}_{t}
\end{array}\right)=\mathbf{D}_{z} E_{t}\left[\mathbf{z}_{t+1}\right]+\mathbf{F}_{z} \mathbf{z}_{t}+\mathbf{D}_{x} E_{t}\left[\mathbf{x}_{t+1}\right]+\mathbf{F}_{x} \mathbf{x}_{t} \\
\mathbf{x}_{t+1}=\mathbf{A} \mathbf{x}_{t}+\boldsymbol{\epsilon}_{t+1}
\end{gathered}
$$

The vector $\mathbf{z}_{t}=\left[\begin{array}{lll}\widehat{i}_{t} & \widehat{y}_{t} & \widehat{h}_{t}\end{array}\right]^{\prime}$ contains the control variables of the system, and the vector $\mathbf{y}_{t}=\left[\begin{array}{llll}\widehat{k}_{t} & \widehat{k}_{t}^{g} & \widehat{b}_{t} & \widehat{w}_{t}\end{array}\right]^{\prime}$ represents the state variables with initial conditions ${ }^{27}$. The co-state variables are in $\boldsymbol{\lambda}_{t}=\left[\begin{array}{ll}\widehat{r}_{t}^{b} & \widehat{c}_{t}\end{array}\right]^{\prime}$, and $\mathbf{x}_{t}=\left[\begin{array}{ll}\widehat{a}_{t} & \widehat{\tau}_{t}^{y}\end{array}\right]^{\prime}$ contains the exogenous variables. Solving (C.1) for $\mathbf{z}_{t}$ and substituting the result into (C.2) reduces the system to

$$
\left(\begin{array}{c}
\mathrm{E}\left[\mathbf{y}_{t+1}\right] \\
\mathrm{E}\left[\boldsymbol{\lambda}_{t+1}\right]
\end{array}\right)=\mathbf{W}\left(\begin{array}{c}
\mathbf{y}_{t} \\
\boldsymbol{\lambda}_{t}
\end{array}\right)+\mathbf{R} \mathbf{x}_{t}
$$

where

$$
\begin{gathered}
\mathbf{W}=-\left(\mathbf{D}_{y \lambda}-\mathbf{D}_{z} \mathbf{C}_{z}^{-1} \mathbf{C}_{y \lambda}\right)^{-1}\left(\mathbf{F}_{y \lambda}-\mathbf{F}_{z} \mathbf{C}_{z}^{-1} \mathbf{C}_{y \lambda}\right) \\
\mathbf{R}=\left(\mathbf{D}_{y \lambda}-\mathbf{D}_{z} \mathbf{C}_{z}^{-1} \mathbf{C}_{y \lambda}\right)^{-1}\left(\mathbf{D}_{z} \mathbf{C}_{z}^{-1} \mathbf{C}_{x}+\mathbf{D}_{x} \mathbf{A}+\mathbf{C}_{z}^{-1} \mathbf{C}_{x} \mathbf{x}_{t}+\mathbf{F}_{x}\right) .
\end{gathered}
$$

The Schur decomposition of the matrix $\mathbf{W}$

$$
\begin{gathered}
\mathbf{W}=\mathbf{T S T}^{-1} ; \mathbf{S}=\mathbf{T}^{-1} \mathbf{W} \mathbf{T} ; \\
\mathbf{S}=\left(\begin{array}{cc}
\mathbf{S}_{y y} & \mathbf{S}_{y \lambda} \\
\mathbf{0} & \mathbf{S}_{\lambda \lambda}
\end{array}\right)=\left(\begin{array}{cc}
\mathbf{T}^{y y} & \mathbf{T}^{y \lambda} \\
\mathbf{T}^{\lambda y} & \mathbf{T}^{\lambda \lambda}
\end{array}\right)\left(\begin{array}{ll}
\mathbf{W}_{y y} & \mathbf{W}_{y \lambda} \\
\mathbf{W}_{\lambda y} & \mathbf{W}_{\lambda \lambda}
\end{array}\right)\left(\begin{array}{cc}
\mathbf{T}_{y y} & \mathbf{T}_{y \lambda} \\
\mathbf{T}_{\lambda y} & \mathbf{T}_{\lambda \lambda}
\end{array}\right)
\end{gathered}
$$

with the eigenvalues outside the unit circle on the diagonal of $\mathbf{S}_{\lambda \lambda}$ allows us to re-express the system given by $(C .4)$ in block recursive form, e.g.

$$
\left(\begin{array}{c}
\mathrm{E}\left[\tilde{\mathbf{y}}_{t+1}\right] \\
\mathrm{E}\left[\tilde{\boldsymbol{\lambda}}_{t+1}\right]
\end{array}\right)=\left(\begin{array}{cc}
\mathbf{S}_{y y} & \mathbf{S}_{y \lambda} \\
\mathbf{0} & \mathbf{S}_{\lambda \lambda}
\end{array}\right)\left(\begin{array}{c}
\tilde{\mathbf{y}}_{t} \\
\tilde{\boldsymbol{\lambda}}_{t}
\end{array}\right)+\left(\begin{array}{l}
\mathbf{Q}_{y} \\
\mathbf{Q}_{\lambda}
\end{array}\right) \mathbf{x}_{t}
$$

where

$$
\begin{gathered}
\left(\begin{array}{c}
\tilde{\mathbf{y}}_{t} \\
\tilde{\boldsymbol{\lambda}}_{t}
\end{array}\right) \equiv \mathbf{T}^{-1}\left(\begin{array}{c}
\mathbf{y}_{t} \\
\boldsymbol{\lambda}_{t}
\end{array}\right) ; \\
\mathbf{T}^{-1} \mathbf{R} \equiv\left(\begin{array}{c}
\mathbf{Q}_{y} \\
\mathbf{Q}_{\lambda}
\end{array}\right) .
\end{gathered}
$$

We next assume that the time path of $\tilde{\boldsymbol{\lambda}}_{t}$ depends linearly on the exogenous process $\mathbf{x}_{t}$, e.g. $\tilde{\boldsymbol{\lambda}}_{t}=\boldsymbol{\Phi} \mathbf{x}_{t}$, and then substitute for $\tilde{\boldsymbol{\lambda}}_{t}$ in (5) to obtain:

$$
\boldsymbol{\Phi} \mathbf{A x}_{t}=\mathbf{S}_{\lambda \lambda} \boldsymbol{\Phi} \mathbf{x}_{t}+\mathbf{Q}_{\lambda} \mathbf{x}_{t}
$$

\footnotetext{
${ }^{27}$ Wages $\widehat{w}_{t}$ can be treated as state because of wage rigidity (equation B.4). We replace $\widehat{r}_{t}^{k}$ using equation (B.8).
} 
Following Klein (2000), we solve (C.6) for vec( $\boldsymbol{\Phi})$, e.g.

$$
\operatorname{vec}(\boldsymbol{\Phi})=\left(\mathbf{A}^{\prime} \otimes \mathbf{I}-\mathbf{I} \otimes \mathbf{S}_{\lambda \lambda}\right)^{-1} \operatorname{vec}\left(\mathbf{Q}_{\lambda}\right)
$$

From $(C .7)$ we can then use the definitions in $(C .5)$ and $(C .1)$ to obtain the policy functions for $\boldsymbol{\lambda}_{t}, \mathbf{y}_{t+1}$, and $\mathbf{z}_{t}$ respectively, e.g.

$$
\begin{gathered}
\boldsymbol{\lambda}_{t}=-\left(\mathbf{T}^{\lambda \lambda}\right)^{-1} \mathbf{T}^{\lambda y} \mathbf{y}_{t}+\left(\mathbf{T}^{\lambda \lambda}\right)^{-1} \mathbf{\Phi} \mathbf{x}_{t} \\
=\mathbf{L}_{\lambda y} \mathbf{y}_{t}+\mathbf{L}_{\lambda x} \mathbf{x}_{t} ; \\
\mathbf{y}_{t+1}=\mathbf{W}_{y y} \mathbf{y}_{t}+\mathbf{W}_{y \lambda} \boldsymbol{\lambda}_{t}+\mathbf{R}_{y} \mathbf{x}_{t} \\
=\left(\mathbf{W}_{y y}+\mathbf{W}_{y \lambda} \mathbf{L}_{\lambda y}\right) \mathbf{y}_{t}+\left(\mathbf{W}_{y \lambda} \mathbf{L}_{\lambda x}+\mathbf{R}_{y}\right) \mathbf{x}_{t} \\
=\mathbf{L}_{y y} \mathbf{y}_{t}+\mathbf{L}_{y x} \mathbf{x}_{t} ; \\
\mathbf{z}_{t}=\mathbf{C}_{z}^{-1} \mathbf{C}_{y \lambda}\left(\begin{array}{c}
\mathbf{y}_{t} \\
\boldsymbol{\lambda}_{t}
\end{array}\right)+\mathbf{C}_{z}^{-1} \mathbf{C}_{x} \mathbf{x}_{t} \\
=\mathbf{C}_{z}^{-1} \mathbf{C}_{y \lambda}\left(\begin{array}{c}
\mathbf{I} \\
\mathbf{L}_{\lambda y}
\end{array}\right) \mathbf{y}_{t}+\left(\mathbf{C}_{z}^{-1} \mathbf{C}_{y \lambda}\left(\begin{array}{c}
\mathbf{0} \\
\mathbf{L}_{\lambda x}
\end{array}\right)+\mathbf{C}_{z}^{-1} \mathbf{C}_{x}\right) \mathbf{x}_{t} \\
=\mathbf{L}_{z y} \mathbf{y}_{t}+\mathbf{L}_{z x} \mathbf{x}_{t} .
\end{gathered}
$$

In state space form, $(C .8-C .10)$ and the equation of motion for $\mathbf{x}_{t}$, i.e. (C.3) can be combined to obtain

$$
\begin{gathered}
\left(\begin{array}{c}
\mathbf{z}_{t} \\
\boldsymbol{\lambda}_{t}
\end{array}\right)=\left(\begin{array}{ll}
\mathbf{L}_{z y} & \mathbf{L}_{z x} \\
\mathbf{L}_{\lambda y} & \mathbf{L}_{\lambda x}
\end{array}\right)\left(\begin{array}{c}
\mathbf{y}_{t} \\
\mathbf{x}_{t}
\end{array}\right) ; \\
\left(\begin{array}{c}
\mathbf{y}_{t+1} \\
\mathbf{x}_{t+1}
\end{array}\right)=\left(\begin{array}{cc}
\mathbf{L}_{y y} & \mathbf{L}_{y x} \\
\mathbf{0} & \mathbf{A}
\end{array}\right)\left(\begin{array}{l}
\mathbf{y}_{t} \\
\mathbf{x}_{t}
\end{array}\right)+\left(\begin{array}{c}
\mathbf{0} \\
\boldsymbol{\epsilon}_{t+1}
\end{array}\right) ;
\end{gathered}
$$

or

$$
\begin{gathered}
\mathbf{w}_{t}=\mathbf{Z} \boldsymbol{\alpha}_{t} \\
\boldsymbol{\alpha}_{t+1}=\mathbf{T} \boldsymbol{\alpha}_{t}+\mathbf{G} \boldsymbol{\epsilon}_{t+1} .
\end{gathered}
$$

\subsubsection{Impulse responses and Watson's RMSAE measure}

From the state-space representation in $(C .11-C .12)$, it is straightforward to derive the impulse responses required for the welfare measure, $\xi$, and the spectrum underlying Watson's RMSAE. For example, the response of $(C .11-C .12)$ to a shock $\epsilon_{0}$ after $t$ time periods is given by

$$
\boldsymbol{\alpha}_{t}=\mathbf{T}^{t} \mathbf{G} \epsilon_{0}
$$




$$
\mathbf{w}_{t}=\mathbf{Z} \mathbf{T}^{t} \mathbf{G} \boldsymbol{\epsilon}_{0} .
$$

The spectrum of the measurement equation, $(C .11)$ is

$$
\mathbf{F}(\omega)_{w}=\mathbf{Z F}(\omega)_{\alpha} \mathbf{Z}^{\prime} ; \omega \in[-\pi, \pi]
$$

and the spectral representation of the $\operatorname{VAR}(1)$ transition equation, $(C .12)$ is

$$
\mathbf{F}(\omega)_{\alpha}=\frac{1}{2 \pi} \mathbf{T}(\omega)^{-1} \mathbf{G} \Sigma \mathbf{G}^{\prime} \mathbf{T}(\omega)^{-\star} ; \omega \in[-\pi, \pi]
$$

where $\boldsymbol{\Sigma}$ is the error variance-covariance matrix of $\boldsymbol{\epsilon}_{t}$, and $\mathbf{T}(\omega)$ is the Fourier transform of the matrix lag polynomial $\mathbf{T}(L)=\mathbf{I}-\mathbf{T} L$ (see Priestly 1981, section 9.4$).{ }^{28}$

\subsection{Appendix D: Welfare Analysis}

\subsubsection{Second-order approximation of within period utility}

For convenience we start by restating household $h^{\prime} s$ instantaneous log-utility function given by (2), i.e.

$$
U_{t}=\ln C_{t}^{h}+\mu \ln \left(1-H_{t}^{h}\right)+\nu \ln \bar{G}_{t}^{c} .
$$

This can re-expressed in terms of aggregate quantities as

$$
U_{t}=\ln \left(\frac{C_{t} Z_{t}}{N_{t} Z_{t}}\right)+\mu \ln \left(1-\frac{H_{t}}{N_{t}}\right)+\nu \ln \left(\frac{G_{t}^{c} Z_{t}}{N_{t} Z_{t}}\right)
$$

or using our notation for stationary variables as

$$
\begin{aligned}
U_{t} & =\ln \left(c_{t} Z_{t}\right)+\mu \ln \left(1-h_{t}\right)+\nu \ln \left(g_{t}^{c} Z_{t}\right) \\
& \Rightarrow \ln c_{t}+\mu \ln \left(1-h_{t}\right)+\nu \ln \left(g_{t}^{c}\right)+(1+\nu) \ln Z_{t}
\end{aligned}
$$

where $c_{t}, h_{t}, g_{t}^{c}$ are stationary consumption, work effort and public consumption respectively and $Z_{t}=z^{t}$ is exogenous labor augmenting technical progress.

Steady-state utility in turn depends on the four argument in (D.1), e.g.

$$
U=U\left(c, h, g^{c} ; Z\right)=\ln c+\mu \ln (1-h)+\nu \ln \left(g^{c}\right)+(1+\nu) \ln (Z) .
$$

\footnotetext{
${ }^{28} L$ is the backshift operator; the superscript ' $\star$ ' denotes the complex conjugate transpose.
} 
The second-order approximation of $(D .1)$ around (D.2) is given by

$$
\begin{aligned}
U_{t}^{s} \simeq & U+\left(U_{4} Z\right) \widehat{Z}_{t}+\frac{1}{2}\left(U_{44} Z^{2}+U_{4} Z_{t}\right)\left(\widehat{Z}_{t}\right)^{2}+\left(U_{1} c\right) \widehat{c}_{t}+\left(U_{2} h\right) \widehat{h}_{t} \\
& +\left(U_{3} g^{c}\right) \widehat{g}_{t}^{c}+\frac{1}{2}\left[\left(U_{11} c^{2}+U_{1} c\right)\left(\widehat{c}_{t}\right)^{2}+\left(U_{22} h^{2}+U_{2} h\right)\left(\widehat{h}_{t}\right)^{2}(D .3)\right. \\
& \left.+\left(U_{33}\left(g^{c}\right)^{2}+U_{3} g^{c}\right)\left(\widehat{g}_{t}^{c}\right)^{2}\right]+O[3]
\end{aligned}
$$

where for any variable $x_{t}, \widehat{x}_{t} \equiv \ln \left(x_{t}-x\right) ; \frac{x_{t}-x}{x} \simeq \widehat{x}_{t}+\frac{1}{2}\left(\widehat{x}_{t}\right)^{2}$; the $s$ superscript denotes the second-order approximation to utility; and $O[3]$ contains all terms of order higher than two. Following the literature, from here forward, these terms will be omitted.

Given the log-form of utility, the following first- and second-partial derivatives in $(D .3)$ are

$$
\begin{array}{cccc}
U_{1}=\frac{1}{c}, & U_{2}=\frac{-\mu}{1-h}, & U_{3}=\frac{\nu}{g^{c}}, & U_{4}=\frac{1+\nu}{Z}, \\
U_{11}=\frac{-1}{c^{2}}, & U_{22}=\frac{-\mu}{(1-h)^{2}}, & U_{33}=\frac{-\nu}{\left(g^{c}\right)^{2}}, & U_{44}=\frac{-(1+\nu)}{Z^{2}}
\end{array}
$$

so that

$$
\left(U_{11} c^{2}+U_{1} c\right)=\left(U_{33}\left(g^{c}\right)^{2}+U_{3} g^{c}\right)=\left(U_{44} Z^{2}+U_{4} Z_{t}\right)=0 .
$$

Substituting these two sets of relations into (D.3) gives the following withinperiod aggregate utility function

$$
U_{t}^{s} \simeq U+(1+\nu) \widehat{Z}_{t}+\widehat{c}_{t}-\left(\frac{\mu}{1-h}\right) \widehat{h}_{t}+\nu \widehat{g}_{t}^{c}-\frac{1}{2}\left(\frac{\mu h}{(1-h)^{2}}\right)\left(\widehat{h}_{t}\right)^{2} .
$$

\subsubsection{Second-order approximation of constraints}

We next take the second-order approximation of our model's stationary constraints around the model's steady-state detailed in Appendix $\mathrm{A}^{29}$, e.g.

$$
\begin{gathered}
\widehat{y}_{t}=\widehat{a}_{t}+\alpha_{1} \widehat{k}_{t}+\alpha_{2} \widehat{h}_{t}+\left(1-\alpha_{1}-\alpha_{2}\right) \widehat{k}_{t}^{g} \\
\frac{c}{y} \widehat{c}_{t} \simeq \widehat{y}_{t}-\frac{i}{y} \widehat{i}_{t}-\frac{g^{c}}{y} \widehat{g}_{t}^{c}-\frac{g^{i}}{y} \widehat{g}_{t}^{i}- \\
\frac{1}{2}\left[\frac{c}{y}\left(\widehat{c}_{t}\right)^{2}+\frac{i}{y}\left(\widehat{i}_{t}\right)^{2}+\frac{g^{c}}{y}\left(\widehat{g}_{t}^{c}\right)^{2}+\frac{g^{i}}{y}\left(\widehat{g}_{t}^{i}\right)^{2}-\left(\widehat{y}_{t}\right)^{2}\right]
\end{gathered}
$$

\footnotetext{
${ }^{29}$ Note that relevant constraints include the production function, the economy's resource constraint and the two capital evolution equations. Further note that (D.5) is an exact expression.
} 


$$
\begin{aligned}
\frac{i}{k} \widehat{i}_{t} \simeq & n z \widehat{k}_{t+1}-\left(1-\delta^{p}\right) \widehat{k}_{t}+ \\
& \frac{1}{2}\left[n z\left(\widehat{k}_{t+1}\right)^{2}-\left(1-\delta^{p}\right)\left(\widehat{k}_{t}\right)^{2}-\frac{i}{k}\left(\widehat{i}_{t}\right)^{2}\right] \\
\frac{g^{i}}{k^{g}} \widehat{g}_{t}^{i} \simeq & n z \widehat{k}_{t+1}^{g}-\left(1-\delta^{g}\right) \widehat{k}_{t}^{g}+ \\
& +\frac{1}{2}\left[n z\left(\widehat{k}_{t+1}^{g}\right)^{2}-\left(1-\delta^{g}\right)\left(\widehat{k}_{t}^{g}\right)^{2}-\frac{g^{i}}{k^{g}}\left(\widehat{g}_{t}^{i}\right)^{2}\right]
\end{aligned}
$$

where $g^{c}=g_{0}^{c} y$ and $g^{i}=g_{0}^{i} y$.

\subsubsection{Second-order approximation of expected lifetime utility}

Substituting $(B .1-B .4)$ into $(D .4)$ gives

$$
\begin{aligned}
U_{t} \simeq & U+(1+\nu) \widehat{Z}_{t}+\frac{y}{c}\left[\widehat{a}_{t}+\alpha_{2} \widehat{h}_{t}-\frac{g^{c}}{y} \widehat{g}_{t}^{c}-\frac{k}{y}\left\{n z \widehat{k}_{t+1}-\left[1-\delta^{p}+\frac{\alpha_{1} y}{k}\right] \widehat{k}_{t}\right.\right. \\
& \left.+\frac{1}{2}\left[n z\left(\widehat{k}_{t+1}\right)^{2}-\left(1-\delta^{p}\right)\left(\widehat{k}_{t}\right)^{2}-\frac{i}{k}\left(\widehat{i}_{t}\right)^{2}\right]\right\}-\frac{k^{g}}{y}\left\{n z \widehat{k}_{t+1}^{g}-\right. \\
& {\left[1-\delta^{g}+\frac{\left(1-\alpha_{1}-\alpha_{2}\right) y}{k^{g}}\right] \widehat{k}_{t}^{g}+\frac{1}{2}\left[n z\left(\widehat{k}_{t+1}^{g}\right)^{2}-\left(1-\delta^{g}\right)\left(\widehat{k}_{t}^{g}\right)^{2}+D .9\right) } \\
& \left.\left.\frac{g^{i}}{k^{g}}\left(\widehat{g}_{t}^{i}\right)^{2}\right]\right\}-\frac{1}{2}\left[\frac{c}{y}\left(\widehat{c}_{t}\right)^{2}+\frac{i}{y}\left(\widehat{i}_{t}\right)^{2}+\frac{g^{c}}{y}\left(\widehat{g}_{t}^{c}\right)^{2}+\frac{g^{i}}{y}\left(\widehat{g}_{t}^{i}\right)^{2}-\right. \\
& \left.\left.\left(\widehat{y}_{t}\right)^{2}\right]\right]-\left(\frac{\mu h}{1-h}\right) \widehat{h}_{t}+\nu \widehat{g}_{t}^{c}-\frac{1}{2}\left(\frac{\mu h}{(1-h)^{2}}\right)\left(\widehat{h}_{t}\right)^{2} .
\end{aligned}
$$

The above expression can be simplified slightly by using (D.7) for squared private investment and (D.8) for squared public investment,

$$
\begin{aligned}
& \frac{i}{k}\left(\widehat{i}_{t}\right)^{2} \\
\simeq & \frac{k}{i}\left[(n z)^{2}\left(\widehat{k}_{t+1}\right)^{2}+\left(1-\delta^{p}\right)^{2}\left(\widehat{k}_{t}\right)^{2}-2 n z\left(1-\delta^{p}\right) \widehat{k}_{t+1} \widehat{k}_{t}\right] \\
& \frac{g^{i}}{k^{g}}\left(\widehat{g}_{t}^{i}\right)^{2} \\
\simeq & \frac{k^{g}}{g^{i}}\left[(n z)^{2}\left(\widehat{k}_{t+1}^{g}\right)^{2}+\left(1-\delta^{g}\right)^{2}\left(\widehat{k}_{t}^{g}\right)^{2}-2 n z\left(1-\delta^{g}\right) \widehat{k}_{t+1}^{g} \widehat{k}_{t}^{g}\right] .
\end{aligned}
$$


For example, it can be easily shown that $\left(D .7^{\prime}-D .8^{\prime}\right)$ in conjunction with the steady-state conditions for the capital evolution equations ${ }^{30}$ imply

$$
\begin{aligned}
& {\left[n z\left(\widehat{k}_{t+1}\right)^{2}-\left(1-\delta^{p}\right)\left(\widehat{k}_{t}\right)^{2}-\frac{i}{k}\left(\widehat{i}_{t}\right)^{2}\right] } \\
= & -n z\left(1-\delta^{p}\right) \frac{k}{i}\left(\widehat{k}_{t+1}-\widehat{k}_{t}\right)^{2} \\
& {\left[n z\left(\widehat{k}_{t+1}^{g}\right)^{2}-\left(1-\delta^{g}\right)\left(\widehat{k}_{t}^{g}\right)^{2}-\frac{g^{i}}{k^{g}}\left(\widehat{g}_{t}^{i}\right)^{2}\right] } \\
= & -n z\left(1-\delta^{g}\right) \frac{k^{g}}{g^{i}}\left(\widehat{k}_{t+1}^{g}-\widehat{k}_{t}^{g}\right)^{2} .
\end{aligned}
$$

Substituting $\left(D .7^{\prime \prime}-D .8^{\prime \prime}\right)$ into $(D .9)$ gives

$$
\begin{aligned}
U_{t}^{s} \simeq & U+(1+\nu) \widehat{Z}_{t}+ \\
& \frac{y}{c}\left[\widehat{a}_{t}+\alpha_{2} \widehat{h}_{t}-\frac{g^{c}}{y} \widehat{g}_{t}^{c}-\frac{k}{y}\left\{n z \widehat{k}_{t+1}-\left[1-\delta^{p}+\frac{\alpha_{1} y}{k}\right] \widehat{k}_{t}-\frac{1}{2} n z\left(1-\delta^{p}\right)\right.\right. \\
& \left.\frac{k}{i}\left(\widehat{k}_{t+1}-\widehat{k}_{t}\right)^{2}\right\}-\frac{k^{g}}{y}\left\{n z \widehat{k}_{t+1}^{g}-\left[1-\delta^{g}+\frac{\left(1-\alpha_{1}-\alpha_{2}\right) y}{k^{g}}\right] \widehat{k}_{t}^{g}-\frac{1}{2} n z\right. \\
& \left.\left(1-\delta^{g}\right) \frac{k^{g}}{g^{i}}\left(\widehat{k}_{t+1}^{g}-\widehat{k}_{t}^{g}\right)^{2}\right\}-\frac{1}{2}\left[\frac{c}{y}\left(\widehat{c}_{t}\right)^{2}+\frac{i}{y}\left(\widehat{i}_{t}\right)^{2}+\frac{g^{c}}{y}\left(\widehat{g}_{t}^{c}\right)^{2}+\right. \\
& \left.\left.\frac{g^{i}}{y}\left(\widehat{g}_{t}^{i}\right)^{2}-\left(\widehat{y}_{t}\right)^{2}\right]\right]-\left(\frac{\mu h}{1-h}\right) \widehat{h}_{t}+\nu \widehat{g}_{t}^{c}-\frac{1}{2}\left(\frac{\mu h}{(1-h)^{2}}\right)\left(\widehat{h}_{t}\right)^{2} .
\end{aligned}
$$

Finally expected lifetime utility is given by the discounted infinite sum of (D.10), i.e.

$$
E_{0}\left[\sum_{t=0}^{\infty} \beta^{t} U_{t}^{s}\right] .
$$

\subsubsection{The social planner's problem}

In contrast to the DCE derived in section 2.5, the social planner maximizes the expected discounted sum of (D.1) subject to the production function, the economy's resource constraint and the two capital evolution equations only. To do so, the planner chooses the paths of $\left\{c_{t}^{*}, h_{t}^{*}, i_{t}^{*}, k_{t+1}^{*}, y_{t}^{*}, g_{t}^{c *}, g_{t}^{i *}\right.$, $\left.k_{t+1}^{g *}\right\}_{t=0}^{\infty}$. Note that to distinguish between the DCE and planner's solution, a * superscript is employed. The stationary solution to the social planner's problem is

$$
y_{t}^{*}=a_{t}\left(k_{t}^{*}\right)^{\alpha_{1}}\left(h_{t}^{*}\right)^{\alpha_{2}}\left(k_{t}^{g *}\right)^{1-\alpha_{1}-\alpha_{2}}
$$

\footnotetext{
${ }^{30}$ See Appendix A equations $(A .5)-(A .6)$.
} 


$$
\begin{gathered}
y_{t}^{*}=c_{t}^{*}+i_{t}^{*}+g_{t}^{c *}+g_{t}^{i *} \\
n z k_{t+1}^{*}=\left(1-\delta^{p}\right) k_{t}^{*}+i_{t}^{*}-\left(\frac{\alpha^{p}}{2}\right) \widetilde{i}_{t}^{* 2} k_{t}^{*} \\
n z k_{t+1}^{g *}=\left(1-\delta^{g}\right) k_{t}^{g *}+g_{t}^{i *} \\
\frac{\alpha_{2} y_{t}^{*}}{h_{t}^{*}}=\frac{\mu c_{t}^{*}}{\left(1-h_{t}^{*}\right)} \\
\frac{1}{c_{t}^{*}}=\frac{\beta}{n z} E_{t}\left[\frac{z_{t+1}^{k *}}{c_{t+1}^{*}}\right] \\
\frac{1}{c_{t}^{*}}=\frac{\beta}{n z} E_{t}\left[\frac{z_{t+1}^{g *}}{c_{t+1}^{*}}\right] \\
\frac{\nu}{g_{t}^{c *}}=\frac{1}{c_{t}^{*}}
\end{gathered}
$$

where

$$
\begin{gathered}
\widetilde{i_{t}^{*}} \equiv\left(\frac{i_{t}^{*}}{k_{t}^{*}}-\frac{i^{*}}{k^{*}}\right) \\
z_{t+1}^{k *} \equiv\left(1-\alpha^{\widetilde{i_{t}^{*}}}\right)\left\{\frac{\alpha_{1} y_{t+1}^{*}}{k_{t+1}^{*}}+\frac{1-\delta^{p}+\alpha^{p} \widetilde{i_{t+1}^{*}}\left(\frac{i_{t+1}^{*}}{k_{t+1}^{*}}\right)-\frac{\alpha^{p}}{2}\left(\widetilde{i_{t+1}^{*}}\right)^{2}}{1-\alpha^{p}\left(\widetilde{i_{t+1}^{*}}\right)}\right\}
\end{gathered}
$$

and

$$
z_{t+1}^{g *} \equiv \frac{\left(1-\alpha_{1}-\alpha_{2}\right) y_{t+1}^{*}}{k_{t+1}^{g *}}+1-\delta^{g} .
$$

In other words the stationary social planner's (SP) problem is defined by the above system of eight nonlinear stochastic difference equations in $\left\{c_{t}^{*}\right.$, $\left.h_{t}^{*}, i_{t}^{*}, k_{t+1}^{*}, y_{t}^{*}, g_{t}^{c *}, g_{t}^{i *}, k_{t+1}^{g *}\right\}_{t=0}^{\infty}$ for a given path of technology, $\left\{a_{t}\right\}_{t=0}^{\infty}$. Note that in contrast to the DCE: (i) there are no market failures (here in the form of real wage rigidity); (ii) there are no policy failures (here in the form of distortionary taxes); (iii) there is no government debt; and (iv) public consumption and investment are chosen optimally instead of being exogenous. 
Long-run solution of the social planner In the absence of technology shocks, i.e. $\varepsilon_{t}^{*}=0$ for all $t$, the steady-state for the social planner's problem is given by the following system of equations

$$
\begin{gathered}
h^{*}=\frac{\omega_{1} \omega_{2}}{\mu+\omega_{1} \omega_{2}} \\
y^{*}=\left[a_{0}\left(\frac{\alpha_{1} \beta}{n z-\beta\left(1-\delta^{p}\right)}\right)^{\alpha_{1}} h^{* \alpha_{2}}\left(\frac{g_{0}^{i *}}{n z+\delta^{g}-1}\right)^{1-\alpha_{1}-\alpha_{2}}\right]^{1 / \alpha_{2}} \\
c^{*}=\omega_{2}^{-1} y^{*} \\
i^{*}=\left(n z+\delta^{p}-1\right)\left(\frac{\alpha_{1} \beta}{n z-\beta\left(1-\delta^{p}\right)}\right) y^{*} \\
k^{*}=\left(\frac{\alpha_{1} \beta}{n z-\beta\left(1-\delta^{p}\right)}\right) y^{*} \\
k^{g *}=\left(\frac{g_{0}^{i *}}{n z+\delta^{g}-1}\right) y^{*} \\
g^{i *}=\left(\frac{\left(1-\alpha_{1}-\alpha_{2}\right) \beta\left(n z+\delta^{g}-1\right)}{n z-\beta\left(1-\delta^{g}\right)}\right) y^{*} \\
g^{c *}=\nu c^{*}
\end{gathered}
$$

where,

$$
\begin{gathered}
\omega_{1}^{*} \equiv \alpha_{2} \\
\omega_{2}^{*} \equiv \frac{n z-\beta\left(1-\delta^{p}\right)}{\left[n z-\beta\left(1-\delta^{p}\right)\right]\left(1-g_{0}^{c *}-g_{0}^{i *}\right)-\left(n z+\delta^{p}-1\right) \alpha_{1} \beta}, \\
g_{0}^{c *} \equiv \frac{g^{c *}}{y^{*}}
\end{gathered}
$$

and

$$
g_{0}^{i *} \equiv \frac{g^{i *}}{y^{*}} .
$$

Implementing the long-run solution of the social planner To go from the long-run DCE to the SP's long-run, requires that $\left(1-\tau_{0}^{y}\right)\left(1-\tau_{0}^{s}\right)=1$ or

$$
\tau_{0}^{s}=\frac{-\tau_{0}^{y}}{\left(1-\tau_{0}^{y}\right)}<0 .
$$


In other words, we need an output subsidy to offset the distortionary income tax in the long-run. Hence long-run lump-sum transfer/tax changes from (A.11) to:

$$
g_{0}^{t *}=0.6(n z)\left(1-\beta^{-1}\right)-g_{0}^{c *}-g_{0}^{i *}+\tau_{0}^{y}-\frac{\tau_{0}^{y}}{\left(1-\tau_{0}^{y}\right)}
$$

which is always negative so that it works as a lump-sum tax.

\subsubsection{Implications for the approximate welfare function}

To eliminate the endogenous linear deviations terms in $(D .9)$ we make use of the social planner's long-run optimality conditions in $(D .20-D .27)$. For example, substituting $(D .16)$ and $(D .19)$ into $(D .10)$ allows us to eliminate the $\widehat{h}_{t}$ and $\widehat{g}_{t}^{c}$ terms. Specifically, since $\frac{\nu}{g^{c *}}=\frac{1}{c^{*}}$, the two terms with $\widehat{g}_{t}^{c}$ sum to zero. Similarly, since $\frac{\alpha_{2} y^{*}}{h^{*}}=\frac{\mu c^{*}}{\left(1-h^{*}\right)}$, the two terms in $\widehat{h}_{t}$ sum to zero.

In $(D .10)$ we also have linear deviations terms in private and public capital, i.e. $n z \widehat{k}_{t+1}-\left[1-\delta^{p}+\frac{\alpha_{1} y^{*}}{k^{*}}\right] \widehat{k}_{t}$ and $n z \widehat{k}_{t+1}^{g}-\left[1-\delta^{g}+\frac{\left(1-\alpha_{1}-\alpha_{2}\right) y^{*}}{k^{g *}}\right] \widehat{k}_{t}^{g}$. It is straightforward to show that the social planner's long-run optimality conditions for private and public capital, see $(D .17-D .18)$, imply

$$
\frac{n z}{\beta}\left(\beta \widehat{k}_{t+1}-\widehat{k}_{t}\right)=n z \widehat{k}_{t+1}-\left[1-\delta^{p}+\frac{\alpha_{1} y^{*}}{k^{*}}\right] \widehat{k}_{t}
$$

and

$$
\frac{n z}{\beta}\left(\beta \widehat{k}_{t+1}^{g}-\widehat{k}_{t}^{g}\right)=n z \widehat{k}_{t+1}^{g}-\left[1-\delta^{g}+\frac{\left(1-\alpha_{1}-\alpha_{2}\right) y^{*}}{k^{g *}}\right] \widehat{k}_{t}^{g}
$$

in the within period utility function. Then, in the overall utility function, we have

$$
\begin{aligned}
\frac{n z}{\beta} \widehat{k}_{0}= & \frac{n z}{\beta} E_{0}\left[\left(\widehat{k}_{0}-\beta \widehat{k}_{1}\right)+\beta\left(\widehat{k}_{1}-\beta \widehat{k}_{2}\right)+\ldots+\beta^{t}\left(\widehat{k}_{t}-\beta \widehat{k}_{t+1}\right)\right. \\
& \left.+\beta^{t+1}\left(\widehat{k}_{t+1}-\beta \widehat{k}_{t+2}\right)\right]
\end{aligned}
$$

and similarly

$$
\begin{aligned}
\frac{n z}{\beta} \widehat{k}_{0}^{g}= & \frac{n z}{\beta} E_{0}\left[\left(\widehat{k}_{0}^{g}-\beta \widehat{k}_{1}^{g}\right)+\beta\left(\widehat{k}_{1}^{g}-\beta \widehat{k}_{2}^{g}\right)+\ldots+\beta^{t}\left(\widehat{k}_{t}^{g}-\beta \widehat{k}_{t+1}^{g}\right)\right. \\
& \left.+\beta^{t+1}\left(\widehat{k}_{t+1}^{g}-\beta \widehat{k}_{t+2}^{g}\right)\right]
\end{aligned}
$$


which are constants. Note that the above two expressions are as in Edge (2003, p. 16). Given the above, we can now write the approximate overall welfare function $(D .11)$ without the endogenous levels terms as

$$
\begin{aligned}
& E_{0}\left[\sum_{t=0}^{\infty} \beta^{t} U_{t}^{s}\right] \\
\simeq & \left(\frac{y^{*}}{c^{*}}\right)\left[\left(\frac{k^{*} n z}{y^{*} \beta}\right) \widehat{k}_{0}+\left(\frac{k^{g *} n z}{y^{*} \beta}\right) \widehat{k}_{0}^{g}\right]+E_{0}\left[\sum _ { t = 0 } ^ { \infty } \beta ^ { t } \left(U+(1+\nu) \widehat{Z}_{t}\right.\right. \\
& +\left(\frac{y^{*}}{c^{*}}\right) \widehat{a}_{t}+\left(\frac{y^{*}}{c^{*}}\right) \frac{1}{2}\left[\left(\frac{k^{*} n z}{y^{*}}\right)\left(1-\delta^{g}\right) \frac{k^{*}}{i^{*}}\left(\widehat{k}_{t+1}-\widehat{k}_{t}\right)^{2}+\right. \\
& \frac{k^{g *} n z}{y^{*}}\left(1-\delta^{g}\right) \frac{k^{g *}}{g^{i *}}\left(\widehat{k}_{t+1}^{g}-\widehat{k}_{t}^{g}\right)^{2}-\left\{\frac{c^{*}}{y^{*}}\left(\widehat{c}_{t}\right)^{2}+\frac{i^{*}}{y^{*}}\left(\widehat{i}_{t}\right)^{2}+\right. \\
& \left.\left.\left.\left.\frac{g^{c *}}{y^{*}}\left(\widehat{g}_{t}^{c}\right)^{2}+\frac{g^{i *}}{y^{*}}\left(\widehat{g}_{t}^{i}\right)^{2}-\left(\widehat{y}_{t}\right)^{2}\right\}\right]-\frac{1}{2}\left(\frac{\mu h^{*}}{\left(1-h^{*}\right)^{2}}\right)\left(\widehat{h}_{t}\right)^{2}\right)\right] .
\end{aligned}
$$

Equation (D.29) corresponds to equation (16) in the main text. 
Figure 1: Net welfare from fiscal stabilisation of $1 \%$ permanent productivity shock
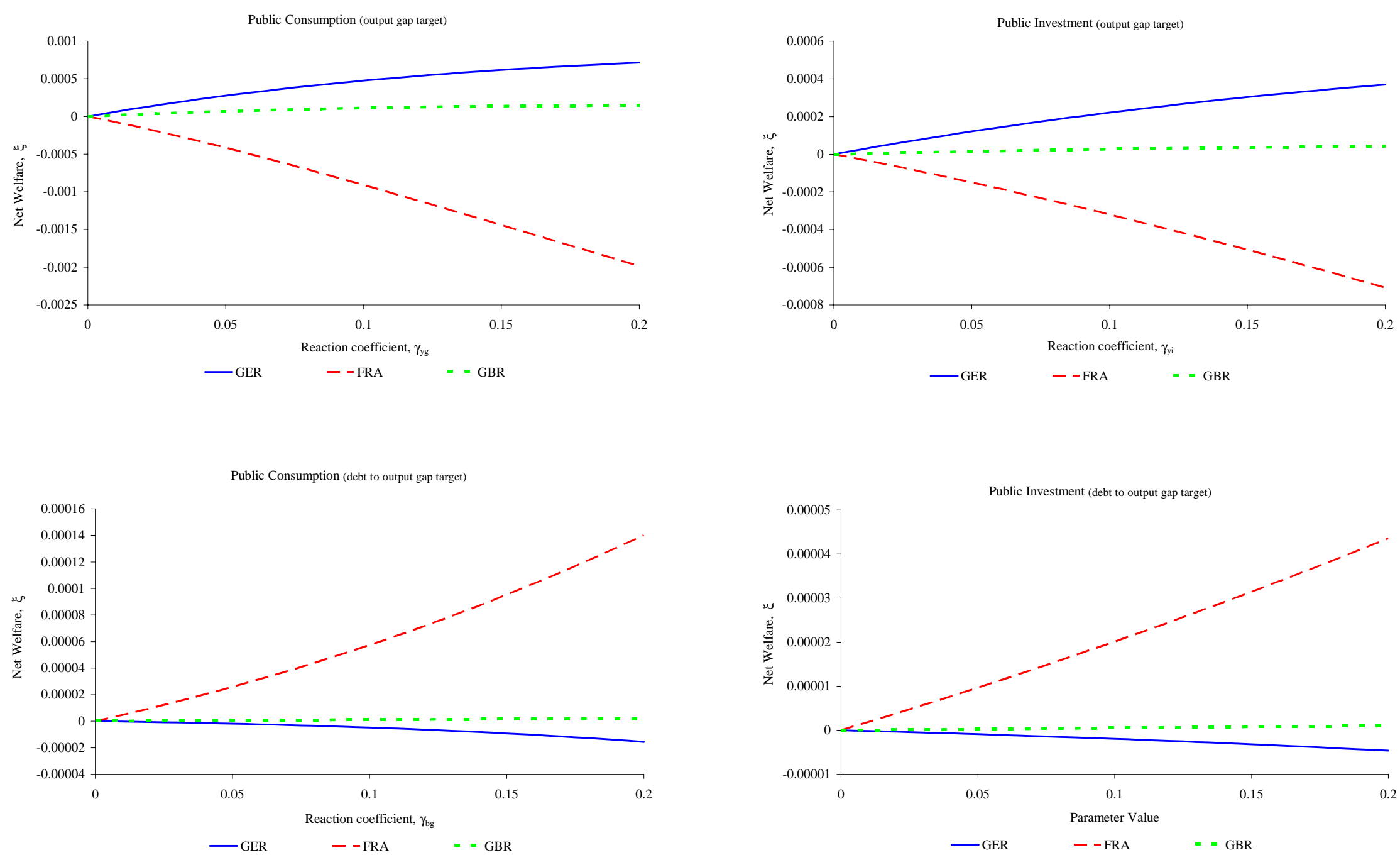
Figure 2: Net welfare from fiscal stabilisation of 5\% permanent productivity shock
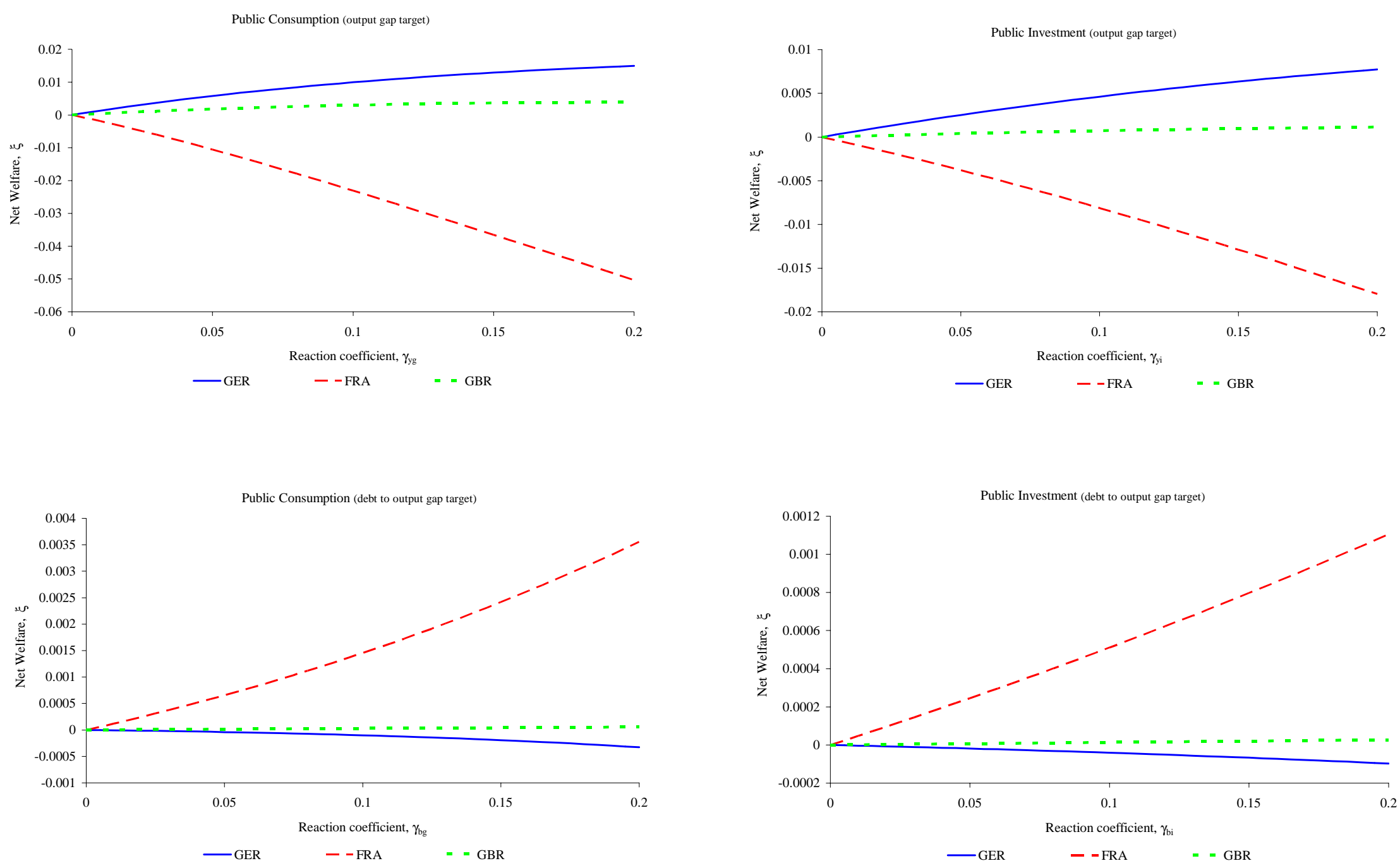